ANUARIO DE Estudios MEDIEVALES 42/2, julio-diciembre de 2012, pp. 601-628

ISSN 0066-5061

doi:10.3989/aem.2012.42.2.08

\title{
SUPERAR LA FRONTERA: MECANISMOS DE INTEGRACIÓN TERRITORIAL ENTRE EL CEA Y EL PISUERGA EN EL SIGLO X ${ }^{1}$
}

\author{
BEYOND THE BORDER: \\ MECHANISMS OF TERRITORIAL INTEGRATION \\ BETWEEN THE CEA AND THE PISUERGA IN THE 10th CENTURY
}

\author{
Álvaro CARVAJAL CASTRO \\ Universidad de Salamanca
}

\begin{abstract}
Resumen: Las diferentes estructuras territoriales que se desarrollaron entre el Cea y el Pisuerga en el siglo $X$ fueron fruto de procesos de producción del espacio particulares. El estudio de su formalización en el marco institucional asturleonés nos ayudará a analizar los recursos y mecanismos políticos empleados por la monarquía y los poderes territoriales principales para consolidar su poder. En último término, nos permitirá comprender mejor los procesos de integración territorial que tuvieron lugar como consecuencia de la expansión de la monarquía asturleonesa sobre la Meseta del Duero en la Alta Edad Media.
\end{abstract}

Palabras clave: Alta Edad Media; Ansúrez; Banu Gómez; espacio; estructuras territoriales; poder.

\begin{abstract}
The different territorial structures that developed in the region between the Cea and the Pisuerga rivers during the 10th century were the outcome of particular processes in the production of space. The study of their formalization within the astur-leonese institutional framework will help us to analyze the political resources and mechanisms employed by both the monarchy and the main regional elites in order to strengthen their power. Ultimately, it will help us to get a better understanding of the processes of territorial integration that took place as the astur-leonese kingdom expanded over the Duero plateau during the Early Middle Ages.
\end{abstract}

Keywords: Early Middle Ages; Ansúrez; Banu Gómez; space; territorial structures, power.

\section{SUMARIO}

1. Introducción.- 2. El panorama historiográfico en torno a los territorios entre el Cea y el Pisuerga en el siglo X.- 3. Los procesos de producción de dos estructuras territoriales diferentes.- 3.1. Los Ansúrez y Monzón.- 3.2. Los dominios de los Banu Gómez.- 4. Conclusión: los mecanismos de integración territorial entre el Cea y el Pisuerga en el siglo X.- 5. Bibliografía citada.

\footnotetext{
${ }^{1}$ Abreviaturas utilizadas: $C D M C=\mathrm{G}$. Martínez Díez, Colección documental del monasterio de San Pedro de Cardeña; $C D M D$ = C.M. Reglero de la Fuente, El monasterio de San Isidro de Dueñas; CDCL $I=$ E. Sáez, Colección documental del archivo de la Catedral de León I; CDCL III = J.M. Ruiz Asensio, Colección documental del archivo de la Catedral de León III; CDME = J.M. Ruiz Asensio; I. Ruiz Albi; M. Herrero Jiménez, Colección documental del monasterio de San Román de Entrepeñas; CDMO = J. de Álamo, Colección diplomática de San Salvador de Oña; CDMS I = J.M. Mínguez, Colección diplomática del Monasterio de Sahagún (siglos IX y X); CDMS II = M. Herrero de la Fuente, Colección Diplomática del Monasterio de Sahagún II; PITTM = "Publicaciones de la Institución Tello Téllez de Meneses".
} 


\section{INTRODUCCIÓN ${ }^{2}$}

Durante gran parte del siglo X, la zona comprendida entre el río Pisuerga y el Cea conoció la implantación de dos estructuras territoriales de gran relevancia: el condado de Monzón, cuya titularidad ostentaron los Ansúrez, y el espacio englobado bajo el dominio de los Banu Gómez. Se trata de una región ${ }^{3}$ de gran interés historiográfico, dado el papel que estos grupos aristocráticos jugaron a lo largo del siglo. Sin embargo, la alta Edad Media del interfluvio Cea-Pisuerga ha sido tradicionalmente abordada, primero, desde la perspectiva de una historia institucional de corte tradicional; y, posteriormente, desde las historias particulares de las diferentes entidades monásticas que se implantaron allí. El resultado es, a día de hoy, un gran desconocimiento de las dinámicas propias de la zona, ya que, si bien la historia institucional nos ha permitido considerar la integración de las élites en el reino asturleonés, lo ha hecho desde la perspectiva de la monarquía. Por otro lado, el estudio de los dominios monásticos, aunque aporta una información fundamental para el estudio de los desarrollos socioespaciales, no nos permite, dada la cronología relativamente tardía de la mayor parte de las fuentes disponibles ${ }^{4}$, estudiar el proceso inicial de formación de las estructuras territoriales, de desarrollo de las familias magnaticias y de implantación del dominio monárquico en la región.

La historiografía se ha visto, además, condicionada por la interpretación de los enfrentamientos entre León y Castilla entre los siglos X y XIII. La tensión entre ambas estructuras políticas jugó, efectivamente, un papel importante en el desarrollo de la región. El problema es que los historiadores llegaron a convertirla en un auténtico topos ${ }^{5}$ : la lucha plurisecular entre León y Castilla por el dominio de la zona y la consideración de ésta como frontera, se asumieron como claves explicativas del pe-

${ }^{2}$ Este trabajo ha sido desarrollado en el marco de una Beca del programa de Formación del Profesorado Universitario (FPU) del Ministerio de Educación (Ref.: AP2008-03525). Agradezco a José María Mínguez Fernández, Iñaki Martín Viso e Isaac Martín Nieto los comentarios realizados a las versiones previas de este artículo, así como las apreciaciones de los evaluadores, que han contribuido a mejorar este trabajo.

${ }^{3}$ Como ámbito geográfico, presenta importantes contrastes entre la zona norte, de carácter montañoso, y la zona sur, en plena meseta. Sin embargo, está bien articulado por cursos fluviales que lo recorren de norte a sur. Lo poco que conocemos acerca de las bases sociales de la época nos muestra cierta heterogeneidad, pero existían agregados -fundamentalmente estructuras territoriales y dominios aristocráticos- que contribuyeron a darle coherencia.

${ }^{4}$ Entidades que, como San Isidro de Dueñas, San Román de Entrepeñas o Santa Eufemia de Cozuelos, proporcionan la mayor parte de la documentación sobre la zona, si bien se trata, para el periodo que nos interesa, de apenas unos pocos documentos dispares y de difícil integración en un marco explicativo regional. Algunos monasterios periféricos, como Sahagún, Oña, Cardeña, o Santo Toribio de Liébana, aportan información sobre las élites regionales. A ello se suman fuentes narrativas como la crónica de Sampiro o los Anales Castellanos Primeros. Existe, además, una serie de falsos diplomas en los que se consignan las supuestas donaciones de los Ansúrez a la abadía de Husillos. Aunque algunos autores se basaron en ellos para trazar la historia de este grupo aristocrático (e.g.: J. San Martín Payo, Las primeras donaciones), creo más adecuado, a la luz de una obra reciente sobre la colección documental de la abadía, prescindir de su utilización (D. Marcos Díez, La abadía de Santa María de Husillos).

5 Martínez Díez lo achacó a la pluma de Pérez de Urbel (G. Martínez Díez, Los condados de Carrión y Monzón, p. 245). Aunque la referencia de conflicto inmediata para esta época es el desafío que Fernán González habría representado para los monarcas asturleoneses, este "topos" no se basó tan sólo en la historia del siglo X, sino también en una proyección anacrónica de la interpretación de las divisiones y reunificaciones de los siglos posteriores. A ello se suma la distorsión que se introducía según el tema se abordara desde el punto de vista leonés -como Justiniano Rodríguez (J. Rodríguez, Ramiro II) - o castellano -como Pérez de Urbel (J. Pérez de Urbel, Historia del Condado de Castilla)-. 
riodo. Se ocultó así la rica "historia regional"6 del interfluvio Cea-Pisuerga que, como veremos, puede permitirnos comprender mejor tanto las peculiaridades de la zona como el proceso de su integración en el contexto socio-político general. De hecho, habida cuenta de las diferencias que presentan, por un lado, Monzón y los Ansúrez; y, por otro, los dominios de los Banu Gómez, podemos hablar ya no sólo de una historia regional, sino de diferentes historias subregionales. Ello nos permitirá profundizar, mediante un análisis comparado, en cada una de estas realidades territoriales.

En este sentido, el objetivo de este artículo es considerar detenidamente el momento inicial de la integración de estos espacios en el ámbito institucional asturleonés, así como su papel en el contexto político de la época, desde el análisis de los marcos de acción socio-política de sus élites. Pretendo con ello contribuir a rellenar algunos vacíos y plantear alternativas a las interpretaciones tradicionales, con el fin de insertar la historia de la región en un panorama historiográfico más amplio.

\section{EL PANORAMA HISTORIOGRÁFICO EN TORNO A LOS TERRITORIOS ENTRE EL CEA Y EL PISUERGA EN EL SIGLO X}

Al abordar el estudio de esta región salta a la vista un problema inmediato: el de la proyección documental e historiográfica de las categorías institucionales del reino asturleonés, tales como conde o condado sobre las realidades sociopolíticas de la zona. De esta proyección se deriva la enorme atención que los historiadores han prestado a los principales grupos aristocráticos. Casi se podría decir que la historia de esta región ha sido, fundamentalmente, la de sus familias magnaticias. Una historia que, además, se supeditaba a la de los grandes procesos políticos de la monarquía asturleonesa, marcados por la llamada "Reconquista" y, como señalé anteriormente, por la pugna entre León y Castilla. Estudiosos como Pérez de Urbel o Justiniano Rodríguez llegaron así a personalizar en los Ansúrez y en los Banu Gómez las tendencias históricas generales y, en particular, las de estos espacios sociales.

Sin embargo, si bien la referencia a la existencia de condados es constante en la bibliografía, sólo Monzón aparece categorizado así en las fuentes ${ }^{7}$. Por el contrario, San Román, Carrión o Saldaña jamás son consignados como tales en todo el siglo X. Sí es verdad que las fuentes se refieren a ciertos magnates como condes, pero hay que tener en cuenta que esto no quiere necesariamente decir que participaran plenamente en las instituciones asturleonesas ${ }^{8}$. Lo mismo ocurre en el caso de otro término común en los documentos de la región, el de territorio $^{9}$, que acaso no refleje sino estructuras territoriales configuradas con anterioridad a su inserción en el reino asturleonés. Debemos, por tanto, tener cuidado: el reconocimiento institucional puede encubrir a veces realidades de poder anteriores. Por ello, y a pesar de las dificultades que plantean las fuentes, recuperar la historia regional pasa por reconsiderar no sólo la historia de estas élites en sí mismas, sino también la de los marcos socioespaciales en que tuvo lugar su acción política ${ }^{10}$.

${ }^{6}$ I. Martín Viso, La monarquía asturleonesa.

CDMC, doc. 42.

${ }^{8}$ C. Estepa, La Castilla primitiva (750-931), p. 273.

${ }^{9}$ Con el ánimo de hacer una distinción precisa entre las estructuras territoriales y su forma institucional, utilizaré la cursiva para territorio como traslado directo de las menciones documentales en el sentido que se le da en éstas.

${ }^{10}$ Sin perjuicio de la reconstrucción prosopográfica, si bien esta labor ya ha sido abordada con detalle en M. Torres, Linajes nobiliarios de León y Castilla. 


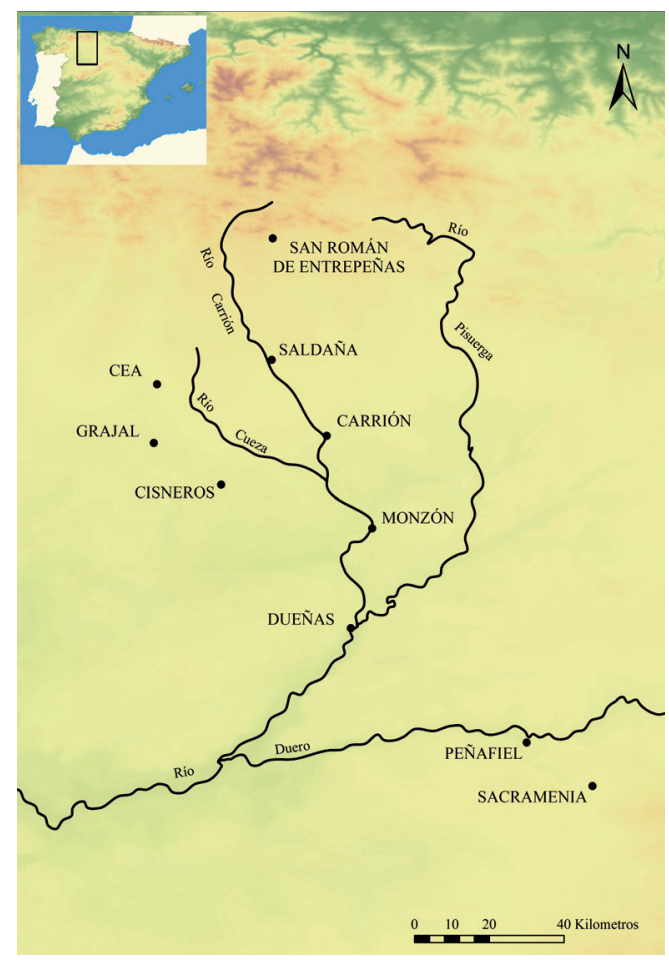

Fig. 1. Principales centros territoriales mencionados en el texto.

Para ello, es necesario revisar algunos de los planteamientos tradicionales y formular nuevas preguntas. Por ejemplo, como luego veremos, los historiadores han manifestado una gran preocupación por determinar el origen geográfico de los grupos aristocráticos. ¿Por qué se le atribuía tanta importancia a esta cuestión? Acaso porque, en un contexto historiográfico dominado por las ideas de reconquista y repoblación, su movilidad se interpretaba como indicador de los flujos poblacionales que supuestamente los nobles arrastraban a remolque de las campañas militares contra los musulmanes ${ }^{11}$. Sin embargo, una vez reconocida la pervivencia de comunidades de población en la meseta del Duero y de fórmulas de organización socioespacial anteriores a la implantación del reino asturleonés, el origen geográfico de estas élites pierde importancia. No toda, pero sí la suficiente como para dar mayor relevancia a factores más interesantes, tales como su posición social inicial y el contexto en que alcanzaron cierta preeminencia, u otros como la capacidad y los límites de acción y de proyección de su poder. A ello se suman las preguntas sobre las condiciones y consecuencias de su integración en el marco institucional del reino, sobre la interacción con los monarcas asturleoneses, etc.

11 Así, se establecía un origen lebaniego para las poblaciones que desde el siglo IX habrían empezado a ocupar los espacios del norte palentino, lo que concordaba con la hipótesis entonces sostenida sobre la procedencia de los Banu Gómez, cuyo núcleo patrimonial se situaba en Liébana (J. González, Siglos de Reconquista, p. 156). 
Realizar estas preguntas sólo es posible desde una perspectiva analítica que evite caer tanto en el anacronismo como en la proyección de categorías institucionales que no se corresponden con las realidades políticas y socioespaciales de la época y región consideradas. Es por ello que he preferido utilizar la expresión "estructura territorial" para referirme a los marcos socioespaciales de la acción política. De esta forma, intento evitar una identificación directa entre las estructuras que pudieron existir con anterioridad a su inserción en el marco institucional asturleonés y las circunscripciones propias del reino. Entiendo por estructura territorial el espacio articulado por relaciones sociales que definen un marco normativo característico y una identidad propia, independientemente de sus dimensiones geográficas y de su grado de complejidad $^{12}$. Se trata de una noción que puede contribuir al análisis del reino asturleonés desde una perspectiva que, en palabras de Matthew Innes, en lugar de buscar instituciones, estudie la génesis y transmisión del poder: esto es, que examine las estructuras de la acción social y las estrategias políticas que se podían desarrollar en el marco de estas estructuras ${ }^{13}$.

La propia monarquía constituía, en este sentido, una estructura territorial que albergaba, a su vez, estructuras de menor rango. Por ello, resulta más interesante ver el conjunto de regiones que formaban el reino como un sistema caracterizado no sólo por un entramado institucional, sino, fundamentalmente, por un marco de relaciones estructurales socioespaciales que integraba unidades discretas, aunque interrelacionadas entre sí, y en el que se podrían distinguir varios niveles de complejidad, que se corresponderían con otras tantas escalas de acción. Éstas pueden definirse como la conjunción de posibilidades, expectativas y limitaciones de actuación derivadas de las condiciones socioeconómicas e institucionales que se daban en un determinado espacio. En este sentido, las estructuras subregionales pueden entenderse como una síntesis entre, por un lado, el proceso de estructuración espacial a nivel local y supralocal; y, por otro, el de implantación de la monarquía sobre el territorio ${ }^{14}$. A ello se añade una concepción de las estructuras subregionales como mediadoras entre la acción política de la monarquía y el ejercicio de poder a escala local ${ }^{15}$.

Este sistema, abordado desde una perspectiva espacial, nos permite, además, ver en un mismo plano, abstrayéndonos de las variaciones diacrónicas o de la adscripción nominal del espacio a uno u otro ámbito de poder, los momentos anterior y posterior a la integración de los espacios en el entramado del reino asturleonés. Podríamos así incluso plantear la posibilidad de que el poder de la monarquía astur-

\footnotetext{
${ }^{12}$ Estas estructuras se plasmarían históricamente de formas muy diferentes: una comunidad de valle, una aldea y su término o los propios territorios son ejemplos históricos de este tipo de estructuras. De todos modos, ésta no pretende ser más que una definición, podríamos decir, de trabajo. He recurrido a la expresión "marco normativo" en el sentido que le da Godelier en relación con la propiedad y la explotación productiva del territorio (M. Godelier, Lo ideal y lo material, pp. 100-106; véase también una aplicación de esta noción en J.J. Larrea Conde, Aldeas navarras y aldeas del Duero). En ningún caso tendría la dimensión jurídica o jurisdiccional que sí tendrían los términos territorio o condado como productos institucionales del reino asturleonés. Debo añadir que para Godelier el marco normativo o, por decirlo con otras palabras, las reglas o normas sociales, representan a la vez una limitación, pero también una oportunidad para la acción. Con este doble sentido, podemos entender el término "territorialidad", tal y como lo define R. Sack, como mecanismo de control, pero también como oportunidad para la acción de los individuos o grupos con capacidad de poder (R. Sack, Human Territoriality, pp. 1-2).

${ }^{13}$ M. Innes, State and Society, p. 9 (traducción propia).

${ }^{14}$ N. Smith, W. Dennis, The Restructuring of Geographical Scale, p. 168; A. Paasi, Place and region, p. 542.

${ }^{15}$ M. Innes, State and Society, p. 259.
} 
leonesa, al proyectar su influencia sobre la región -incluso de manera indirecta, es decir, sin que se hubiera producido una integración formal-, hubiera contribuido a la consolidación de unas estructuras sociales territorializadas, basadas en la existencia de una diferenciación social previa ${ }^{16}$. Esto se habría traducido en la afirmación de unas determinadas élites, sin que ello supusiera una imposición automática del poder regio sobre el espacio.

Dentro de las posibilidades que brinda este marco interpretativo, Julio Escalona, en uno de los esfuerzos más recientes por repensar la historia de la región, se refería al condado de Monzón como una forma política que habría resultado del proceso de expansión de un poder que buscaba una franja de espacio entre el condado castellano y otros centros importantes, como Saldaña o Carrión ${ }^{17}$. Efectivamente, es dudoso que esta circunscripción, tal y como se revela en las fuentes, tuviera sentido fuera del contexto territorial del reino asturleonés. Sin embargo, sabemos, como luego expondré, que tenía una estructuración territorial propia anterior a su integración en el mismo. ¿Es esto un indicador suficiente para considerar que Monzón pudo servir de base para una lógica de expansión aristocrática? ¿O cabe aún pensar que dependió realmente de una política orquestada por el poder regio? ${ }^{18}$ ¿Qué situación se dio en el caso de los dominios de los Banu Gómez, en los que la intervención regia parece mucho menos intensa?

Estos grupos aristocráticos, al igual que les habría ocurrido a otros de menor importancia, se habrían encontrado, por un lado, con la necesidad de negociar su relación con la monarquía; y, por otro, de encontrar estrategias para hacer efectivo el ejercicio de su poder a nivel local. Uno de los mecanismos de los que habrían podido disponer habría sido la transferencia de tierras, que además de revelarnos la existencia de núcleos patrimoniales que podrían atestiguar el origen social de estas élites, podría indicarnos los ámbitos socioespaciales en los que tenían la capacidad de crear sus propias redes de poder ${ }^{19}$. En este sentido, José M. Mínguez ha expuesto recientemente una de las líneas de trabajo en las que aún debemos profundizar para conocer mejor la historia de esta región ${ }^{20}$. Aunque este historiador no escapa totalmente al problema historiográfico de la supeditación de la historia regional a la historia de la "frontera" entre las formaciones políticas leonesa y castellana, plantea acertadamente la necesidad de una consideración exhaustiva de las bases sociales del poder aristocrático. Su propuesta es, por tanto, complementaria a la de J. Escalona. La diferencia entre ambos estriba en que éste enfatiza la importancia de lo que denomina territorialidades o patrones territoriales previos a la implantación del poder señorial ${ }^{21}$, mientras que J.M. Mínguez centra su atención en el desarrollo socioeconómico de las realidades campesinas -conforme al modelo que presenta en otras obras ${ }^{22}-$, así como en la expansión patrimonial y jurisdiccional de determinados actores señoriales, tales como el monasterio de Sahagún o los distintos

${ }^{16}$ En línea con el modelo de relación centro-periferia que se plantea en M. Rowlands, Centre and periphery.

17 J. Escalona, Aproximación a un análisis, p. 289.

18 Ibidem.

${ }^{19}$ Lo que Chris Wickham define como "políticas de la tierra" (C. Wickham, Framing the Early Middle Ages, p. 58). Véase también M. Innes, State and Society, pp. 68 y 93.

20 J.M. Mínguez, La frontera del Carrión, ponencia presentada en el Congreso Internacional Regnum Legionis (910-1230), celebrado en León entre el 25 y el 29 de octubre de 2010. Agradezco a José María Mínguez el haberme facilitado el texto de la ponencia.

${ }^{21}$ J. Escalona, Aproximación a un análisis, p. 285.

22 Véase, por ejemplo, J.M. Mínguez, Las sociedades feudales. 
grupos aristocráticos. Por desgracia, debemos esperar hasta el siglo XI para tener una imagen más completa de todos estos aspectos ${ }^{23}$.

Ambas líneas de investigación comparten, por tanto, un mismo problema: la ausencia de fuentes documentales tempranas. El desarrollo de la investigación arqueológica en la región no se encuentra lo suficientemente avanzado como para proporcionarnos indicaciones sobre los procesos regionales de transformación anteriores al siglo X. Además, ha estado excesivamente condicionado por la presencia de restos de época romana y tardoantigua de la importancia de la villa de La Olmeda. Y ello a pesar de que existen yacimientos de gran interés historiográfico para la Alta Edad Media como Monte Cildá -aunque se encuentra fuera del ámbito geográfico de interés para este artículo- o El Castellar, en Villajimena, que fueron esgrimidos en su momento como prueba de la continuidad del poblamiento en el valle del Duero ${ }^{24}$. Un conocimiento más profundo de la entidad y proyección territorial de estos asentamientos en cada periodo histórico nos ayudaría a conocer los desarrollos de larga duración en la región e insertarlos con mayor adecuación en los modelos historiográficos propuestos ${ }^{25}$. A ello debemos sumar los resultados de las cada vez más avanzadas investigaciones sobre las aldeas altomedievales como las que se están realizando en el País Vasco ${ }^{26}$. Aunque estas experiencias no se puedan trasladar directamente a la región que aquí nos ocupa, resultan interesantes de cara a la formulación de hipótesis sobre la emergencia de élites locales, por lo que no podemos perder de vista estas propuestas a la hora de articular un nuevo marco explicativo que dé potencialmente cabida a las futuras aportaciones de la arqueología.

\section{LOS PROCESOS DE PRODUCCIÓN DE DOS ESTRUCTURAS TERRITORIALES DIFERENTES}

A partir de los planteamientos delineados en el apartado anterior, pretendo llevar a cabo un análisis de los procesos de emergencia y consolidación de los Ansúrez y de los Banu Gómez, así como del primer desarrollo de las estructuras territoriales que sirvieron de marco socioespacial para su acción. Las diferencias apreciables entre ambos casos aconsejan una estrategia de estudio comparado que centraré en el análisis del origen geográfico y social de las familias magnaticias, en su capacidad para ge-

${ }^{23}$ Por ejemplo, la donación que Elvira Fáfilaz realizó a San Román de Entrepeñas en 1027 revela la expansión patrimonial de los Banu Gómez en el norte de la cuenca del Carrión (CDME, doc. 2).

${ }^{24}$ Los dos yacimientos fueron excavados en los años 60. Los arqueólogos quisieron ver trazas de continuidad en el poblamiento a lo largo de los siglos altomedievales (M.Á. García Guinea et al., El Castellar; idem et al., Excavaciones en Monte Cildá: Campañas de 1963 a 1965; idem et al., Excavaciones de Monte Cildá: Campañas de 1966 a 1969). El uso que se hizo de las interpretaciones arqueológicas para justificar los argumentos contra la despoblación altomedieval de la Meseta, en especial en el caso de El Castellar, fue, cuanto menos, poco prudente (A. Barbero y, M. Vigil citaron estos trabajos a través de la lectura que de ellos hacía García de Cortázar; véase J.Á. García de Cortázar, El dominio del monasterio, p. 101, n. 12; A. Barbero, M. Vigil, La formación del feudalismo, p. 225, n. 80). A pesar de que muestran unas secuencias de ocupación muy interesantes, faltan datos para poder hacer una correcta interpretación de la entidad de los yacimientos en cada momento histórico, por lo que no se puede valorar adecuadamente la aparente continuidad poblacional.

${ }^{25}$ Especialmente relevante para el caso de Monte Cildá, como para el resto de núcleos en altura -como Saldaña o Monzón-, es el artículo S. Castellanos, I. Martín Viso, The local articulation of central power, especialmente p. 13.

${ }^{26}$ Véase, por ejemplo, J.A. Quirós Castillo, Early Medieval Villages in Spain; y, más recientemente, A. Vigil Escalera-Guirado, J.A. Quirós Castillo, Early Medieval Rural Societies. 
nerar redes de poder, en el grado y forma en que se implantaron en el territorio y, por último, en la relación que mantuvieron con la monarquía asturleonesa.

\subsection{Los Ansúrez y Monzón}

La interpretación historiográfica sobre el surgimiento de la estructura territorial con centro en Monzón constituye un claro ejemplo de la deformación histórica que introdujo el institucionalismo tradicional. Por un lado, J. Pérez de Urbel o J. Rodríguez se basaron en la primera mención documental a un conde y a un condado de Monzón para fechar la creación de éste en el año $943^{27}$. Para estos historiadores, la victoria en la batalla de Simancas del 939 habría supuesto una oportunidad para las ambiciones expansionistas castellanas, las cuales se pondrían posteriormente de manifiesto con el levantamiento, aunque frustrado, de Fernán González y Diego Muñoz contra Ramiro II en el año $944^{28}$. Monzón se interpretaba, por tanto, como una manifestación de la pericia -o perversidad según qué historiador ${ }^{29}$ - política de Ramiro II, quien se habría anticipado a las maniobras de estos condes poniendo freno a sus posibilidades de expansión territorial mediante la creación de ese condado.

Frente a ellos, G. Martínez Díez, basándose en el hecho de que la zona habría sido repoblada en la misma época que Castrojeriz -años 882 u 883- propuso que el condado de Monzón había sido creado con anterioridad a la batalla de Simancas ${ }^{30}$. El autor reforzaba su argumento recurriendo a lo que consideraba indicios de que Asur Fernández ostentaba, ya en el año 939, la dignidad condal: en primer lugar, el hecho de que en los Anales Castellanos Primeros figure al frente de su propia hueste; en segundo, la trayectoria de su padre, Fernando Ansúrez, quien llegó a figurar como conde en Castilla en el año 929 y aparece con tal título en las fuentes musulmanas ${ }^{31}$. Su propuesta es interesante en la medida en que

${ }^{27} C D M C$, doc. 42. J. Rodríguez como Martínez Díez mantuvieron una controversia sobre un documento, supuestamente datado en el año 937, en el que se hace mención a un "Assuri dominans Mendunie" (J. Rodríguez, Ramiro II, doc. 27). El documento ya había sido publicado por E. Sáez (E. Sáez, Los ascendientes de San Rosendo, doc. 6), quien indicaba que podía ser dado por auténtico, aunque posiblemente estuviera mal datado (ibidem, p. 120, n. 34). J. Rodríguez, quien situó el origen del condado en el año 943, negó que Mendunie pudiera ser identificado con Monzón, proponiendo Medina de Rioseco como alternativa (J. Rodríguez, Ramiro II, p. 238). Martínez Díez, para quien el condado era anterior al año 943, se aferró al problema de la datación para considerar que, incluso aunque el documento hiciera referencia a Monzón, no podía fecharse con anterioridad al 943 (G. Martínez Díez, El condado de Castilla, p. 378). Es interesante comprobar cómo cada historiador vio la necesidad de modificar ya la localización de Mendunie, ya la cronología del documento, en función de la tesis que sostenía a priori.

28 J. Pérez de Urbel, Sampiro, p. 328.

${ }^{29}$ Así, para Pérez de Urbel, Asur Fernández era un esbirro de Ramiro II (J. Pérez de Urbel, Historia del condado de Castilla, pp. 436 y ss., p. 536), mientras que para J. Rodríguez era un hombre honrado y merecedor de la confianza del rey (J. Rodríguez, Ramiro II, pp. 219 y 236-240).

${ }^{30}$ Aunque siempre habría sido posterior, en cualquier caso, al cese de Fernando Ansúrez al frente del condado castellano, que el autor fecha en el 931, año en que vemos aparecer por primera vez a Gutier Núñez (G. Martínez Díez, El condado de Castilla, p. 380). Sobre las tesis de Martínez Díez sobre Monzón, véase también idem, Los condados de Carrión y Monzón.

${ }^{31}$ G. Martínez Díez, El condado de Castilla, p. 381. Martínez Díez recurre a Ibn Hayyān para sustentar su argumento. El problema es que él mismo afirma en esa misma obra, que las fuentes musulmanas "designaban frecuentemente como conde a cualquier dignatario cristiano, a cualquier alcaide de una fortaleza, que se encontraba muy lejos de gozar de esa dignidad" (ibidem, p. 257), lo que debilita su argumento. 
abre la posibilidad de reconocer en Monzón una estructura territorial anterior a su primera mención documental como condado. No obstante, al buscar a toda costa la sanción institucional de Asur Fernández como comes, Martínez Díez se cerró la puerta a una formulación en términos que no fueran los propios de la monarquía asturleonesa.

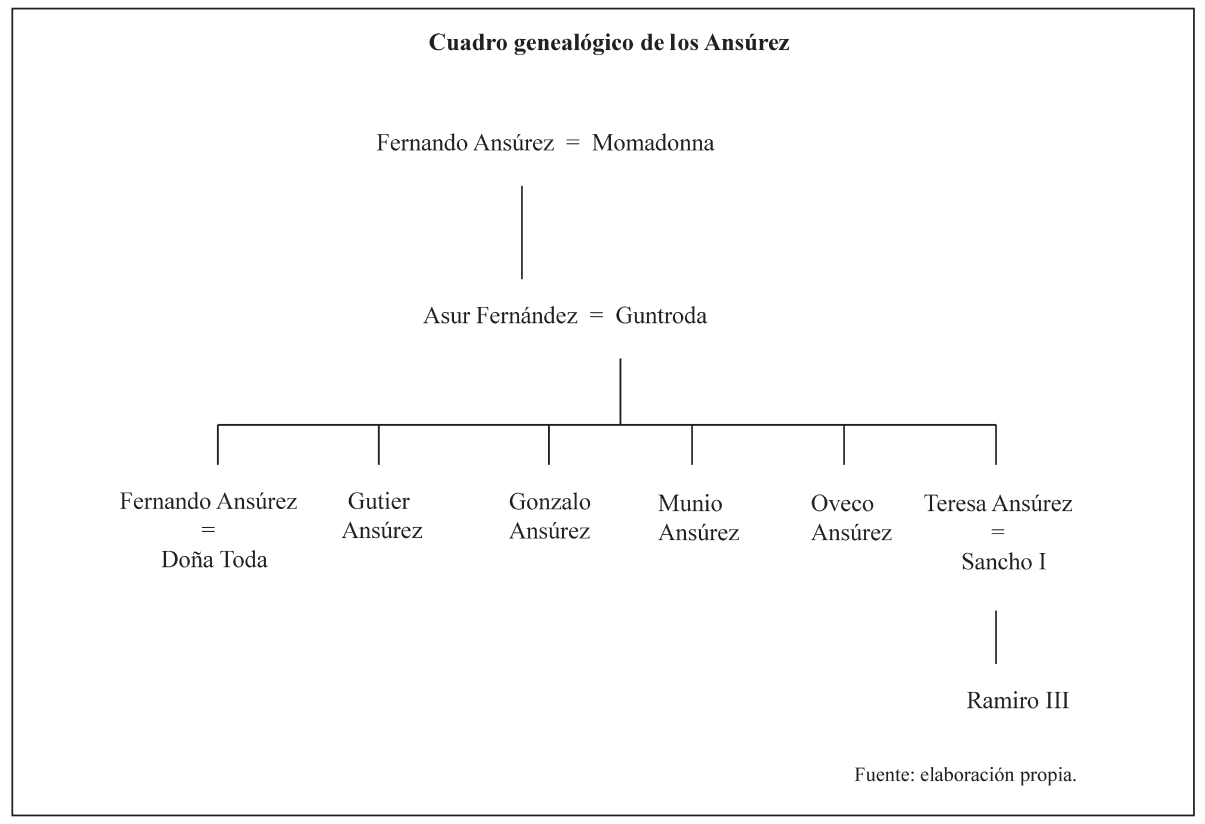

Fig. 2. Cuadro genealógico de los Ansúrez.

Tenemos noticias de que, a principios del siglo X, Monzón era el centro de una estructura territorial que tenía una cierta complejidad. En el año 904, el presbítero Gratón realizó una amplia donación al infante Gonzalo, hijo de Alfonso III ${ }^{32}$. Una lectura directa de los términos utilizados para definir las distintas territorialidades que menciona el documento nos llevaría a pensar en la existencia de una gran estructura territorial, calificada como suburbio, que tendría como centro el castrum de Monzón. Esta estructura habría englobado otro castrum, el de Cisneros, así como una serie de lugares tales como Santa María de Husillos, Santa María de Carejas - cerca de Paredes de Nava-, o Quintana Mediana, en Campos. Creo, sin embargo, que la interpretación de este documento no es tan sencilla y que se podría, al menos, proponer otra lectura.

En primer lugar, el término suburbio ha tendido a identificarse con la mención al suburbio de León, centro del poder regio en la misma época. Por ello, algunos autores han atribuido a Monzón una preeminencia territorial superior a la que

${ }^{32}$ CDCL I, doc. 17. 
habría tenido de haber sido un mero castrum $^{33}$. Sin embargo, el término no tiene por qué ser interpretado más allá del sentido que le atribuye Carlos Estepa: como espacio sometido -aunque aún no podamos saber muy bien de qué manera- al marco normativo y a la autoridad que emanaban de un determinado centro ${ }^{34}$. Por ejemplo, la utilización del término en referencia a Sanabria, que no habría gozado, ni mucho menos, del mismo rango que la ciudad de León, indica, como también señaló el propio C. Estepa, que su uso no suponía atribuir a un centro administrativo unas características socioeconómicas más desarrolladas ${ }^{35}$. Por tanto, aunque suburbio parezca indicar un nivel de territorialidad superior, esta representación del espacio podría no reflejar una jerarquización real. Es posible que Cisneros articulara ya en el 904 la estructura territorial propia que encontramos claramente documentada en el año $946^{36}$. Un documento más tardío, del año 986, hace referencia a la existencia de unas élites locales que se hacen visibles a través de la mención a un conventum $^{37}$. Si aceptáramos la posibilidad de leer esta estructuración socioespacial de manera retrospectiva, sumado al hecho de que Cisneros se encuentra a una distancia suficiente de Monzón como para haber sido el centro de un territorio propio, podríamos pensar que, a pesar de que el único suburbio mencionado en la donación del presbítero Gratón sea el de Monzón, esto no implicaba la subordinación de Cisneros a Monzón, sino, simplemente, que a éste se le atribuía una mayor importancia en términos de representación del espacio.

Por otro lado, aunque es indudable que Santa María de Husillos pertenecía al territorio del castrum de Monzón, no resulta tan claro que ocurriera lo mismo en el caso de Carejas y de Campos. Estos topónimos parecen definir territorialidades particulares que a su vez contenían otros lugares: Santa María en el caso del primero; Quintana Mediana en el del segundo ${ }^{38}$. ¿Estaban Carejas y Campos englobados en Monzón? Carejas se encuentra a mitad de camino entre Monzón y Cisneros. ¿No podría igualmente haber pertenecido al espacio controlado por el segundo? Parte del problema de interpretación deriva de la estructura de la frase que consigna los lugares en los que se donan los bienes, ya que, tal y como ha sido editada, enfatiza la preeminencia de Monzón y confiere la idea de que se trataba de un centro que controlaba todos los demás lugares. Sin embargo, creo que, en base a la consideración anterior sobre el término suburbio, es posible proponer una lectura diferente. La puntuación propuesta por el editor es:

in suburbio de kastro quod dicitur Monteson, id est: ecclesia uocabulo Sancte Marie, quod fuit dirupta a paganis et ego, cum Dei iuuamine, restauraui eam, siue et kasas quas ibidem construxi, et uinea quod ibidem manibus meis plantaui, et sernas in locos predictos: ibidem a Santa Maria, in Karelias; in Campos, ad Quintana Mediana, ad illas fontes, ad illo archo; in Cenisarios, ad illum kastrum ${ }^{39}$.

${ }^{33}$ J.J. Sánchez Badiola, La configuración, p. 311.

${ }^{34}$ C. Estepa, Problemas de terminología, pp. 104-107.

${ }^{35}$ C. Estepa, El alfoz castellano, p. 313. El monasterio de San Martín de Castañeda, por ejemplo, se sitúa, según el formulario empleado en la redacción de su documentación, "in confinum urbis Senabrie", ya desde una primera mención en el año 952 (Á. Rodríguez González, El tumbo del monasterio, doc. 4). Agradezco a I. Martín Viso la indicación.

${ }^{36}$ CDMS I, doc. 105.

${ }^{37}$ CDMS I, doc. 334.

${ }^{38}$ Existe aún hoy una ermita dedicada a Nuestra Señora de Carejas, cerca de Paredes de Nava.

${ }^{39}$ CDCL I, doc. 17. 
Pienso que sería más adecuada la lectura et uinea quod ibidem manibus meis plantaui. Et sernas in locos predictos, ibidem, estableciendo una cesura antes de la enumeración de los lugares en que se donan las sernas. De esta forma, quedaría más claro que la utilización de ibidem antes de $a$ Sancta Maria, aunque podría parecer que enlaza este lugar con los bienes donados en Monzón, se refiere en realidad a esos locos predictos que se presentan a continuación ${ }^{40}$.

En definitiva, si bien resulta clara la existencia de una estructura con al menos dos niveles de territorialidad y con centro en Monzón, no se puede afirmar que con suburbio se hiciera referencia a un nivel de complejidad superior. Esta situación contrasta con la que se documenta casi cuarenta años después, en el año 943, cuando Asur Fernández donó a Cardeña el lugar de Fonte Aderata, en la Sierra de Montejo ${ }^{41}$. Este documento es muy interesante, ya que contiene la primera mención tanto al condado y a su constitución interna como a la presencia de un personaje intitulado como conde en Monzón. Es, además, la única expresión clara de la dimensión espacial de esta estructura territorial. En ella, lo primero que se aprecia es un alto grado de formalización institucional, ya que vemos actuar no sólo al máximo representante político, sino también a un agente que operaba en una escala inferior: el sayón Hanni Ovécoz ${ }^{42}$. Por otro lado, la estructura territorial del condado aparece bien definida. El documento nos habla de dos castella, Peñafiel y Sacramenia, desde los que se ejercía un poder jurisdiccional sobre los lugares del entorno ${ }^{43}$. Ambos eran núcleos importantes en la jerarquización socioespacial de la zona: centros desde los que las élites locales habrían ejercido el poder sobre los núcleos del entorno con anterioridad a su incorporación al condado de Monzón ${ }^{44}$. Se trataba de centros que dominaban territorialidades con marcos normativos propios, aunque de menor escala, y que habrían funcionado como elementos de transmisión del poder condal. Su constitución interna no era, por tanto, distinta de aquellas estructuras territoriales que las fuentes califican de territorios. Por otro lado, al englobar estos centros, Monzón alcanzó una escala de complejidad en la organización del espacio superior a la que hasta entonces había tenido.

¿Cómo se produjo este salto cualitativo? La presencia de Asur Fernández en el documento del año 943, así como la asociación historiográfica entre los Ansúrez y el condado de Monzón nos obliga a preguntarnos, en primer lugar, en qué medida se debió a la actuación de este grupo aristocrático. Esto nos remite a la cuestión sobre su origen social y sobre su capacidad de inserción en las estructuras territoriales. Tradicionalmente, su estatus aristocrático se ha tomado como algo dado, mientras que una donación de Fernando Ansúrez en Rubena, cerca de Burgos, en el año 921, así como una intervención posterior de Asur Fernández en un pleito en la zona, sirvieron para

${ }^{40}$ Podría tratarse de un recurso estilístico, ya que la construcción de la frase parece alternar, por un lado, lugares y territorialidades en forma de espejo de acuerdo con el esquema lugar-territorio/ territorio-lugar (Santa María-Carejas / Campo-Quintana Mediana); y, por otro, el empleo de las preposiciones in y ad. El ibidem equivaldría formalmente al "ad illas fontes, ad illo archo" que sucede a "Quintana Mediana". La ausencia del verbo no es significativa, ya que se trata de algo recurrente en la documentación.

${ }^{41}$ CDMC, doc. 42.

42 Acaso el Hanni Ovécoz que en el año 968 realizó una donación al monasterio de Santa Eufemia de Cozuelos (M.D. Guerrero Lafuente y M.A. Álvarez Castillo, Los inicios del monacato en Palencia, doc. 4).

43 "Sit a parte de meo comdato uel in iure de ipsis castellis qui in circuitu eius sunt, id est, unum Penna Fidele et alterum Sacramenia" (CDMC, doc. 42).

${ }^{44}$ I. Martín Viso, Repoblaciones, territorios, pp. 276-277. 
justificar el origen geográfico y patrimonial de los Ansúrez ${ }^{45}$. Dada la parquedad de las noticias, es arriesgado afirmar nada, pero lo cierto es que se trata del único lugar en la que actúan más de una vez. Es significativo, además, que el objeto de la donación de Fernando Ansúrez fuera una serna, lo que podría indicar una cierta preponderancia social $^{46}$. Sin embargo, no está tan claro que Asur Fernández, aunque reclame los bienes como propios, aparezca en calidad de propietario. Lo hace como juez en un litigio y con el título de conde en Castilla, por lo que su capacidad jurisdiccional podría derivarse del ejercicio de ese cargo ${ }^{47}$. En el mismo sentido, el valor de los bienes que recibió en concepto de confirmación al efectuar la donación a Cardeña parecería indicar que hizo uso de una potestad condal, y no patrimonial, a instancias del propio monasterio ${ }^{48}$.

En cualquier caso, estas acciones tuvieron lugar en entornos muy alejados del que sería el núcleo de su dominio político. Y es que da la sensación de que los Ansúrez nunca gozaron de una base patrimonial sólida en Monzón. Realizaron escasas transacciones de bienes, de cuya propiedad conocemos el origen. Gonzalo Ansúrez vendió a Sahagún, en el año 960, unos bienes que había recibido por una profiliación ${ }^{49}$. Por su parte, Fernando Ansúrez obtuvo una serie de villas gracias al favor de Ordoño III, villas que luego donó a Sahagún en el año $976^{50}$. Incluso en el caso de la donación de la iglesia de Santa Coloma, que Fernando Ansúrez reclamaba como propia, a San Isidro de Dueñas en el año 976, la acción parece reflejar no la base patrimonial de este personaje, sino su capacidad de actuación como conde en Monzón, en la medida en que ésta le hubiera permitido reestructurar redes eclesiásticas en su beneficio. Aunque estos documentos no nos informan sobre la base patrimonial original de los Ansúrez, sí nos muestran indicios de que los hijos de Asur Fernández se encontraba en una situación sociopolítica preponderante a nivel regional: eran objeto de donaciones por parte de los monarcas, sus miembros constituían un grupo atractivo para aquellos personajes de menor rango que buscaban vincularse a las redes magnaticias y, además, parecen mostrar una cierta capacidad -aunque tardía, en relación con el establecimiento del dominio del grupo familiar en Monzón-para crear redes de poder mediante transacciones de tierras.

La estrecha relación con los reyes asturleoneses constituye, como vimos antes, uno de los elementos recurrentes en la historiografía tradicional ${ }^{51}$. Ahora bien, ¿cuál fue la dimensión real de la relación entre los Ansúrez y los reyes asturleoneses? ¿Cómo influyeron estos en la configuración del condado de Monzón? Un diploma de Ordoño II del año 915 se presentaba como prueba del establecimiento temprano del vínculo entre el grupo aristocrático y la monarquía asturiana. Se trata, sin embargo, de un documento que plantea dudas sobre su autenticidad ${ }^{52}$. Por otra parte, Sampiro nos

${ }^{45} C D M C$, doc. 12; $C D M O$, docs. 3 y 4. Pérez de Urbel situó su origen en el entorno de los Montes de Oca en base tanto a estos documentos como a un argumento, difícilmente sostenible, basado en la existencia de topónimos como Villanasur y Villasur de Herreros (J. Pérez de Urbel, Historia del Condado de Castilla, p. 305).

${ }^{46}$ J.Á. García de Cortázar, La serna, pp. 122-123; véase también E. Botella Pombo, La serna.

47 CDMC, doc. 12; CDMO, docs. 3 y 4.

48 "Accepimus a uobis in honore duos kaballos cum sella, quattuorcentas obelias seu et panno de algupa" (CDMC, doc. 42).

${ }^{49}$ CDMS II, doc. 369.

${ }^{50}$ CDMS I, docs. 285 y 293.

${ }^{51}$ Véase la nota 29. La idea se recoge también en J. González, Siglos de Reconquista.

${ }^{52}$ M. Lucas Álvarez, La documentación del Tumbo A, doc. 28. Según precisa el editor, la segunda parte del documento es de dudosa autenticidad, mientras que la tercera está indudablemente interpolada. Asume que los confirmantes pertenecen al año de la data, pero esto no quiere decir que figuraran 
cuenta que, en una fecha imprecisa, Nuño Fernández, un tal Abolmondar Albo y su hijo Diego y Fernando Ansúrez participaron en una acción conjunta contra Ordoño II, que los derrotó en Tebular ${ }^{53}$. Si efectivamente pudiéramos pensar que Fernando Ansúrez participaba ya en el marco institucional del reino, podríamos entender este hecho como un intento -fallido- de renegociación de su posición. De lo contrario, pone en duda que el grupo aristocrático estuviera ya integrado en las instituciones asturleonesas.

Más adelante, en el año 929, Fernando Ansúrez aparece en los documentos como conde en Castilla. El cargo habría contribuido a dar un mayor relieve a la familia ${ }^{54}$. ¿Cómo accedió a esta posición? Hipotéticamente, en una situación en la que el poder castellano no estaba todavía plenamente consolidado, sino que era en gran medida un poder fluido, la posición de Fernando Ansúrez habría sido equivalente a la de magnates como aquellos que aparecen junto a él en Tebular -el propio Nuño Fernández alcanzó el título de conde en Castilla ${ }^{55}$-, por lo que, en un proceso de interacción competitiva, habría podido pugnar por hacerse con el poder condal. Ello implicaría asumir que su núcleo patrimonial estaba efectivamente radicado en la zona burgalesa, que era de una cierta importancia -la suficiente como para permitirle entrar en competencia por el poder condal castellano-, y que la donación a Cardeña pudo haber sido un intento por construir una red de poder más sólida en la zona. Su acceso al título condal, al igual que su participación en la rebelión de Alfonso IV contra Ramiro II, que nos narran las fuentes musulmanas ${ }^{56}$, indicaría que esta posición era más fuerte que la que nos muestran los diplomas.

Sin embargo, se puede apreciar que la situación contrasta con la que se dio unos años después. Frente a la aparente autonomía de Fernando Ansúrez, su hijo, Asur Fernández, parece haber estado más condicionado por la relación con el poder regio. Asur Fernández fue un personaje de creciente importancia a lo largo del reinado de Ramiro II. Aparece por primera vez en los diplomas regios en el año 936, en los que va cobrando cada vez más relevancia ${ }^{57}$. Se le menciona también en un lugar destacado en el relato que en los Anales Castellanos Primeros se hace de la batalla de Simancas ${ }^{58}$ y ya en el año 943 aparece como conde en Monzón ${ }^{59}$. El punto álgido, aunque efímero, lo encontramos entre el 944 y el 945, cuando Asur Fernández aparece también ostentando el título condal castellano en un momento en que Fernán González, que junto con Diego Muñoz se había sublevado contra Ramiro II, se encontraba preso ${ }^{60}$. Acaso el monarca impulsó a Asur Fernández con el fin de ejercer un mayor control sobre Castilla cuando el momento era políticamente propicio. Las evidencias de la buena relación entre el magnate y Ramiro II se completan con el matrimonio entre su hija Teresa y Sancho I, padres de Ramiro III. Por otro lado, el proceso de consolidación

en el documento original. Además, y aunque producto de un contexto diferente, existen dos series de documentos falsos en la colección documental de la catedral de León en los que la asociación entre Ordoño II y Fernando Ansúrez es recurrente (CDCL I, docs. 39 y 64; $C D C L I$, docs. 50, 54, 55, 56 y

62). Esto nos obliga a tomar la pretendida mención del 915 aún con mayor cautela.

53 J. Pérez de Urbel, Sampiro, p. 316.

${ }^{54} \mathrm{CDMC}$, docs. 17 y 18.

55 G. Martínez Díez, El condado de Castilla, p. 197.

56 Ibn Hayyān, Crónica del califa 'Abdarrahmān III, p. 244.

${ }^{57}$ La primera mención en $C D M D$, doc. 8. En el 946 llegaría a ocupar la primera posición en un documento dado por Ramiro II (J. Rodríguez, Ramiro II, doc. 61).

58 J.C. Martín Iglesias, Los Annales Castellani, p. 209.

${ }^{59}$ CDMD, doc. 42.

${ }^{60}$ Las menciones a Asur Fernández como conde en Castilla en $C D M C$, p. 46 y CDMO, docs. 3 y 4. La noticia de la rebelión en J. Pérez de Urbel, Sampiro, p. 328. 
de Asur Fernández al frente del condado de Monzón y, posteriormente, su aparición al frente del condado castellano, coinciden con la primera restauración de la sede episcopal palentina -documentada entre el año 940 y 944- en lo que parece haber constituido un intento de integrar más estrechamente los territorios entre el Cea y el Pisuerga en el reino asturleonés a través de la estructura eclesiástica ${ }^{61}$.

Sin embargo, el interés particular que Ramiro II pudiera tener en afianzar su dominio no condensa el proceso que llegó a propiciar la aparición de Monzón como una estructura territorial fuerte en la zona. Esta cuestión se ha explicado hasta ahora atendiendo casi exclusivamente a los aspectos coyunturales, pero aunque es cierto que el momento parecía políticamente apropiado para una proyección más intensa del poder de Ramiro II hacia el oriente de la Meseta, existen otros factores que debemos tener en cuenta, como la temprana actuación regia sobre Dueñas. Desde el punto de vista geoestratégico, este núcleo se encuentra en una posición muy interesante, ya que se ubica en la confluencia entre el Carrión y el Pisuerga. La crónica de Sampiro nos dice que Alfonso III repobló Dueñas en el año 89962. Además, desde muy temprano en el siglo X, los reyes asturleoneses mostraron una especial atención hacia el monasterio de San Isidro de Dueñas. Conservamos varios documentos que consignan donaciones o confirmaciones regias de donaciones anteriores. La serie se inicia con un diploma de García I del año 911 y se prolonga hasta el de Ramiro II del año $936^{63}$. Debemos, por tanto, descartar que el interés regio por el control de la zona fuera una consecuencia inmediata de la fuerza que estaban adquiriendo el condado castellano y los Banu Gómez, ya que se manifiesta con mucha anterioridad. Es interesante comprobar cómo parece haber una relación inversa entre las donaciones realizadas al cenobio y la creciente importancia que cobra Asur Fernández desde, precisamente, el año $936^{64}$, y que, como señalamos anteriormente, culmina con su intitulación como conde en Monzón ${ }^{65}$.

Los Ansúrez se habrían situado al frente de un espacio ya estructurado -como revela la donación del presbítero Gratón ${ }^{66}$ - que podía constituir una mejor plataforma para el ejercicio de un poder de carácter militar. Desde este punto de vista, sin duda habría sido más efectivo que la influencia que los monarcas hubieran podido ejercer mediante la creación de una red eclesiástica y de patronazgo a través del monasterio de San Isidro de Dueñas. Parece, por tanto, que la institucionalización de la estructura territorial de Monzón, así como la promoción de Asur Fernández, respondían a un interés más general por el dominio de esta región. Ahora bien, ¿por qué esperaron tanto los monarcas asturleoneses para consolidar de esta manera su poder? La campaña de Alfonso III no se concentró en el entorno de Dueñas, sino que abarcó un espacio mucho más amplio que habría resultado difícil de integrar. Que la monarquía dispusiera de fuerza suficiente para llevar a cabo una acción en un radio tan amplio

${ }^{61}$ Encontramos menciones a un "Iulianus, episcopus Palentia sedis", en un documento del año 940 y dos documentos del año 944 (G. Cavero Domínguez y E. Martín López, Colección documental I, docs. 55; CDMO, doc. 3; CDMS I, doc. 93). Sobre esta figura, véase G. Martínez Díez, El obispado de Palencia en el siglo X; Á. Vaca Lorenzo, El Obispado de Palencia.

62 J. Pérez de Urbel, Sampiro, p. 305.

${ }^{63} C D M D$, docs $1,2,3,4,7$. Tan sólo la confirmación de Ramiro III de la donación que Fernando Ansúrez hizo de la iglesia de Santa Coloma en el año 976 (CDMD, doc. 15) rompe la ausencia de documentos regios, o sancionados por el poder regio, en el resto del siglo X. Conservamos, eso sí, documentos que constatan el desarrollo patrimonial del cenobio en estos años.

${ }^{64} C D M D$, doc. 8.

${ }^{65} C D M C$, doc. 42.

${ }^{66}$ CDCL I, doc. 17. 
e, incluso, como muestran las donaciones citadas, de apropiarse de bienes fundiarios con los que practicar una "política de la tierra", no implica que los reyes pudieran hacer efectivo un control cotidiano sobre el espacio. La red de patronazgo creada en torno a San Isidro de Dueñas habría sido un primer elemento en la instauración del dominio ${ }^{67}$. Primero, pero no exclusivo, ya que el caso de Gratón o el del presbítero Usquela $^{68}$ ponen de manifiesto que también recurrieron a una vinculación directa con determinadas élites locales. Sólo más tarde habrían tenido la capacidad para colocar a un grupo aristocrático al frente de Monzón y llevar a cabo la plena integración de este espacio en el marco institucional asturleonés. En definitiva, aunque no podemos determinar las razones inmediatas que motivaron este cambio de orientación en el modelo de dominio regio sobre la región, sí podemos afirmar que la formalización del condado respondía a una lógica de integración territorial más profunda que la coyuntura estratégica particular posterior a la batalla de Simancas o que la percepción de la amenaza expansionista castellana.

\subsection{Los dominios de los Banu Gómez}

Es precisamente en esos años cuando los documentos nos revelan la fuerza del otro gran grupo aristocrático de la región: los Banu Gómez. Aunque los historiadores situaron inicialmente su origen geográfico en Liébana, existe hoy consenso en ubicarlo en el norte de la cuenca del Carrión ${ }^{69}$. Su dominio se ha identificado habitualmente con el espacio ocupado por los territorios de San Román, Saldaña y Carrión, que estaban conectados por el río Carrión. La historiografía ha transmitido la idea de una entidad política extensa constituida desde, al menos, el año 940. En esta fecha, Diego Muñoz donó al monasterio de San Román de Entrepeñas una serie de posesiones entre las que se incluían una iglesia en el entorno de Dueñas, así como otra en Arconada, cerca del núcleo actual de Carrión de los Condes ${ }^{70}$. Los historiadores se basaron en la aparición de este magnate como comes Saldanie en el año $950^{71}$ para situar en este núcleo la capital de los dominios. Se ha tendido, pues, a ver una estructura de poder territorialmente homogénea desde sus inicios y en la que el único cambio

${ }^{67}$ Caso semejante al que pudo darse en el Bierzo (I. Martín Viso, La monarquía asturleonesa en el Bierzo). Véase también M. Innes, State and Society, p. 29. Casos similares en otros contextos europeos en J.W. Bernhardt, Itinerant Kingship; y en J. Blair, The Church. doc. 7).

${ }^{68}$ A quien Ordoño II habría comprado una viña que luego Ramiro II donó a San Isidro (CDMD,

${ }^{69}$ Pérez de Urbel mantuvo el origen lebaniego de Diego Muñoz (J. Pérez de Urbel, Historia del condado de Castilla, pp. 449-452). Más recientemente, J. Montenegro Valentín situó su origen en el norte de la cuenca del Carrión, en base a la aparente filiación entre Diego Muñoz y el que habría sido su padre, un personaje llamado Munio Gómez cuyo termino aparece como referencia en un documento del año 915 en la misma zona, el entorno de San Pedro de Cansoles, cerca de Guardo, en la que Diego Muñoz aparecerá vendiendo bienes unos años más tarde (J. Montenegro Valentín, En torno a los orígenes familiares de Diego Muñoz). Su tesis ha sido asumida y defendida por otros historiadores como G. Martínez Díez o M. Torres (G. Martínez Díez, La familia condal de Carrión; M. Torres, Linajes nobiliarios de León y Castilla, pp. 236-239). M. Torres ha intentado rastrear el origen de Munio Gómez en un Gómez que identifica con un magnate alavés. Su hipótesis se basa en el supuesto cautiverio de este Gómez por los musulmanes tras la campaña de Morcuera y en el posterior retorno de su hijo al reino asturleonés (M. Torres, Linajes nobiliarios de León y Castilla, p. 238-239). Se trata de una hipótesis arriesgada y, en cualquier caso, considero más adecuado para mi propósito intentar llevar a cabo una interpretación alternativa desde el análisis de las condiciones socioespaciales en las que encontramos inserto a Munio Gómez.

${ }^{70} C D M E$, doc. 1.

${ }^{71}$ CDMS I, doc. 129. 
reseñable en cuanto a su configuración espacial habría sido el posterior traslado de la capitalidad a Carrión ${ }^{72}$. Las fuentes, sin embargo, nos obligan a matizar esta interpretación, ya que confieren una idea de expansión de norte a sur en un proceso de configuración progresiva del dominio. Este proceso se manifiesta no sólo en la distribución geográfica y cronológica de la documentación -más temprana para San Román, más tardía para Carrión- sino también en la evolución en cuanto al reconocimiento de los espacios como parte del reino asturleonés. Expresiones como el castrum Saldanie, el territorio de Carrione o la mención a la figura condal -comite in-no sólo nos hablan de la producción del dominio de los Banu Gómez, sino también de la representación de estos espacios y de este grupo aristocrático con las categorías propias del contexto institucional asturleonés y, por lo tanto, de su integración en el mismo. ¿Cuál era el contenido histórico concreto de estos términos? Se trata de una pregunta a la que podemos responder a través del análisis de la relación entre el desarrollo de este grupo familiar y el de las estructuras territoriales que dominaron.

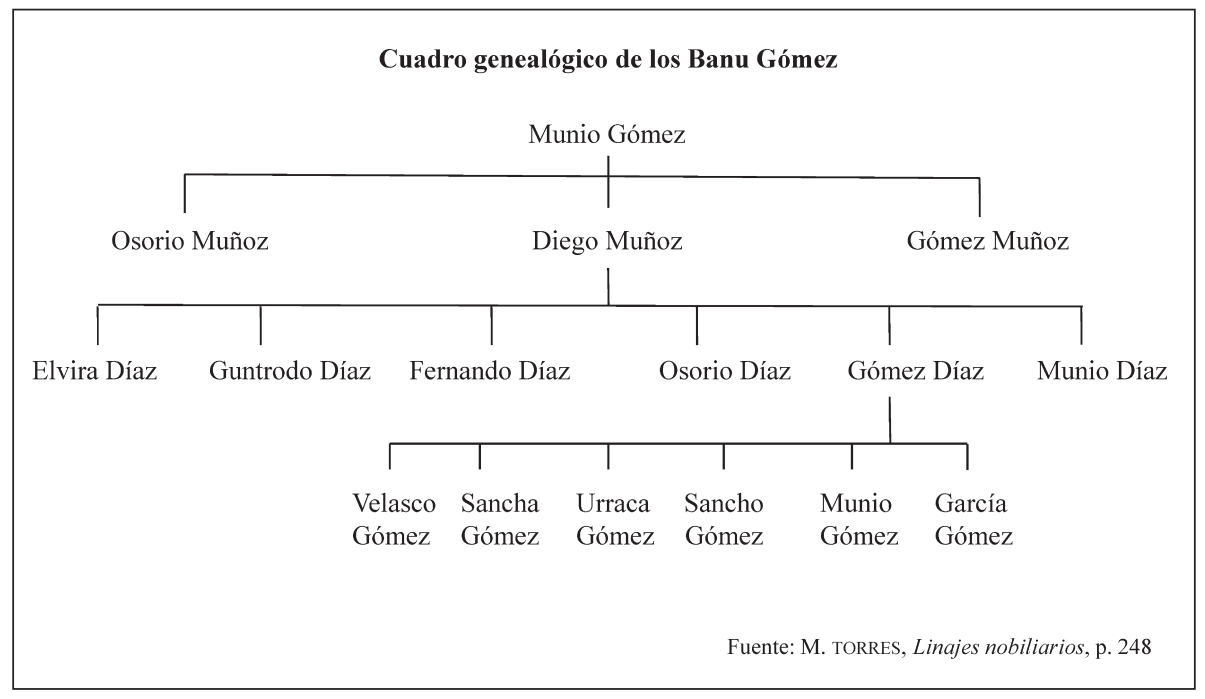

Fig. 3. Cuadro genealógico parcial de los Banu Gómez.

El proceso se habría iniciado en el norte de la cuenca del Carrión. Como señalé anteriormente, hoy en día se acepta que el origen de Diego Muñoz se encontraba en el entorno de Guardo y se identifica a su padre con el Munio Gómez que aparece como propietario en una donación que Ramiro, hijo de Alfonso III, hizo a Sahagún, en el año $915^{73}$. Parte de las referencias espaciales que figuran en este documento coinciden con las que aparecen en la venta que realizó Diego Muñoz en el año 941 en el mismo entorno -el de Ceón ${ }^{74}$. De entre ellas, destaca la mención a las propiedades de los herederos de un personaje llamado Teodisclo, quien precisamente había donado a Ramiro los bienes que éste cedía al monasterio de Sahagún. De hecho, sabemos

\footnotetext{
72 J.A. Pérez Celada, Sobre el origen de Carrión de los Condes.

${ }^{73}$ CDMS I, doc. 12.

${ }^{74}$ CDMS I, doc. 76.
} 
que Teodisclo y su familia intentaron vincularse, mediante donaciones, no sólo a los monarcas asturleoneses, sino también al monasterio de Sahagún ${ }^{75}$. De ello podemos inferir que se trataba de un grupo familiar de relativa importancia y que, posiblemente, habría gozado de cierto prestigio social del que acaso habría emanado una cierta autoridad. Aunque no podemos realizar ninguna aseveración sobre la situación social precisa de Munio, su aparición como posesor de un termino y el desarrollo posterior de su grupo familiar podrían indicar que, en origen, la emergencia de los Banu Gómez se produjo en un contexto similar al que se documenta para Teodisclo, aunque no necesariamente a través de los mismos cauces. Es interesante comprobar cómo en un mismo entorno - precisamente uno, Ceón, en el que las fuentes no dejan constancia de la existencia de centro territorial alguno- tuvieron lugar dos procesos de estructuración del espacio - de constitución de dominios de pequeña escala- similares en su origen, pero de desarrollos divergente. Se trataba de una situación cambiante, de gran fluidez, que afectaba directamente a una monarquía que, a falta de centros territoriales, debía buscar en estas élites locales los mecanismos de control sobre el espacio, pero que, a su vez, podía ayudar a consolidar la posición social de dichas élites. Esto no siempre se traducía en la formalización de emergentes dominios aristocráticos: el de Teodisclo fue dividido a su muerte entre sus hijos, de entre los que no parece que surgiera un heredero que mantuviera la posición social del padre ${ }^{76}$. De Munio, por el contrario, no tenemos evidencias de una relación temprana con la monarquía -aunque esto no quiere decir que no existiera-, si bien sabemos que su hijo no sólo logró mantener su posición social, sino que llegó a alcanzar una mayor cota de poder. Todo ello mediante una estrategia que no parece mediatizada -o que estaba menos mediatizadapor la influencia de la monarquía y que les permitió desarrollar una política propia que incluía la vinculación con un centro religioso que se convertiría en una suerte de monasterio propio: San Román de Entrepeñas ${ }^{77}$. El monasterio se encontraba en un ámbito geográfico en el que el documento del 940 atestigua la presencia de un castillo, lo que indicaría la existencia de un centro de poder en el seno de una estructura territorial jerarquizada, si bien la falta de documentación nos impide profundizar sobre su configuración espacial ${ }^{78}$.

En esa donación del 940, Diego Muñoz incluyó una iglesia en Arconada, en el entorno de Carrión de los Condes; y otra, la de Santiago de Galleta, cerca de Dueñas ${ }^{79}$. ¿Cómo conjugar la idea de un dominio directo aparentemente restringido al norte de la cuenca del Carrión con un ámbito geográfico de actuación tan amplio en una fecha tan temprana? Por un lado, se podría argumentar que un dominio sólidamente construido le habría dado la capacidad para actuar más allá de los límites del ámbito inmediato de ejercicio de su autoridad y que, además, la creación de redes eclesiásticas no necesitaba de un control directo sobre el territorio, sino que, como vimos al hablar de San Isidro de Dueñas, se empleaba como instrumento para el ejercicio del poder a nivel local. De todos modos, se trata de ámbitos concretos y aislados del núcleo patrimonial, por lo que en ningún caso

${ }^{75}$ CDMS I, docs. 12 y 101.

${ }^{76}$ CDMS I, doc. 76.

${ }^{77}$ La importancia de este monasterio en el dominio de los Banu Gómez queda atestiguada en la donación que Elvira Fáfilaz realizó al monasterio en 1027 (CDME, doc. 2).

${ }^{78}$ Una de las referencias espaciales del documento es la "strata que discurret ad castellum" (CDME, doc. 1). Carecemos de documentos sanromaniegos que cubran el periodo entre el 940 y el 1027.

${ }^{79}$ La identificación de la iglesia se puede realizar gracias a un documento de 1153, según indica el editor en el comentario que lo acompaña (CDMD, doc. 60). También en $C D M E$, doc. 24. 
podemos afirmar que los Banu Gómez tuvieran ya entonces un dominio extenso sobre la cuenta del Carrión.

Precisamente, lo que más llama la atención es la ausencia de bienes entre San Román y Carrión, es decir, en Saldaña. A pesar de que este núcleo se ha identificado siempre con el centro de los dominios de los Banu Gómez, las fuentes nos obligan a matizar esta idea. En todo el siglo $X$ tan sólo tenemos una mención a un conde en Saldaña: la de Diego Gómez del año $950^{80}$. Hay que esperar unos cincuenta años, hasta el $1001^{81}$, para ver como conde en Saldaña a García Gómez, quien aparece de nuevo en $1013^{82}$. Entre estas fechas, nada prueba explícitamente la continuidad de su dominio. Además, otros indicios apuntan a que el grupo aristocrático tuvo en Saldaña una débil presencia. Existen documentos que consignan las donaciones que algunos miembros de este grupo aristocrático habrían realizado en el siglo XI y que reflejan un proceso de acumulación patrimonial anterior ${ }^{83}$. Incluyen bienes dispersos por toda la región, fundamentalmente en aquellos territorios como San Román o Carrión, pero las menciones a bienes en Saldaña son muy escasas. Además, a pesar de la fuerza que la historiografía tradicional atribuía al dominio de los Banu Gómez en este territorio, Saldaña llegó a pasar temporalmente a manos de los Alfonso a mediados del siglo $\mathrm{XI}^{84}$. De igual manera, y a diferencia de lo que ocurría en San Román, o de lo que ocurriría en Carrión con la fundación del monasterio San Zoilo en el año $1047^{85}$, la familia tampoco parece haberse vinculado a ningún monasterio importante. Tan sólo tenemos una referencia indirecta a un monasterio de San Juan en Saldaña, al que García Gómez, en su única intervención documentada en este territorio, hizo una donación en un momento que no podemos precisar ${ }^{86}$. Parece, en definitiva, que no lograron generar una red de poder lo suficientemente fuerte como para consolidarse, ni disponían de una base patrimonial como para garantizar la continuidad de su control sobre Saldaña. ¿A qué pudo deberse esta aparente incapacidad para implantar su dominio? La historia de este núcleo es mal conocida. El hecho de que aparezca mencionado como castrum en el documento del año 950 parece indicar que tenía una cierta importancia. ¿Era esto reflejo de la existencia de un centro territorial que jerarquizaba el espacio circundante? ¿Se traducía esta aparente preeminencia en el control real sobre una estructura territorial? Si así era, ¿por qué se mostró tan refractario a la implantación del poder de los Banu Gómez? Si pudiéramos conocer algo sobre su configu-

${ }^{80}$ En el documento se incluye entre los confirmantes "Didacus Monnioz, comes Saldanie" (CDMS I, doc. 129).

${ }^{81}$ L. Sánchez Belda, Cartulario de Santo, doc. 79.

${ }^{82}$ CDCL III, doc. 718. Entre estas dos fechas tan sólo contamos con una referencia expresa a un dominio sobre Saldaña en una donación a San Martín de Turieno, supuestamente fechada en el año 966, al final de la cual se dice que el documento fue dado "regnante rex Sancio in Castella et comite Nuno Monite in Sallania et in Leuanes" Ibidem, doc. 71). J. Montenegro Valentín ha expuesto las razones que le llevan a considerar que este documento es lo suficientemente problemático como para prescindir de su utilización, por lo que las dudas sobre la continuidad del dominio quedan por el momento sin resolver (J. Montenegro Valentín, Santa María de Piasca, p. 173). Sánchez Belda, primer editor, afirmaba que la lectura del documento era, además, muy complicada (L. Sánchez Belda, Cartulario de Santo, p. 85).

${ }^{83}$ Por ejemplo, la donación de Elvira Fáfilaz del año 1027 (CDME, doc. 2) o el documento en el que Elvira Sánchez realiza donación de sus bienes al monasterios de San Salvador del Nogal en el año 1060 (CDMS II, doc. 615).

${ }^{84}$ CDMS II, doc. 465.

85 J.A. Pérez Celada, Documentación del Monasterio, doc. 1. Véase también J.A. Pérez Celada, El monasterio de San Zoilo de Carrión.

${ }^{86}$ CDMS II, doc. 444. 
ración interna, acaso nos encontraríamos con una estructura territorial sólidamente articulada y mostrar una sociedad capaz de ejercer una resistencia efectiva; o bien con un espacio desarticulado social y económicamente cuya dominación no era posible o habría carecido de interés ${ }^{87}$. ¿Por qué entonces adoptar el título de comes en Saldaña? ¿Se trataba de un elemento de representación del poder, de un eco de la importancia que este núcleo había tenido en época visigoda y cuya memoria, como mostraría la crónica de Alfonso III, habría perdurado? ${ }^{88}$ Son muchas más las preguntas que se plantean que las respuestas que se pueden dar-si es que podemos dar alguna. Ante la falta de documentos, un mejor conocimiento de la historia de esta estructura territorial pasa necesariamente por un mejor conocimiento arqueológico de la zona, en especial, del yacimiento de La Morterona ${ }^{89}$.

Para Carrión, por el contrario, las fuentes nos permiten apuntar un poco más lejos en la formulación de hipótesis. Los Banu Gómez consolidaron tanto un dominio político como patrimonial, aunque aparentemente más tarde de lo que la historiografía nos ha transmitido, ya que no existen documentos que permitan corroborar un dominio extenso de los Banu Gómez sobre el conjunto de la cuenca del Carrión hasta el año $979^{90}$. Se trata de una fórmula genérica referida al dominio del conde Gómez Díaz in rium de Carrione y que coincide con la primera mención al dominio que habría ejercido sobre Liébana, del que luego hablaré. No se trata de una mención expresa a un territorio de Carrión -que no aparece como tal antes del $984^{91}$-, pero incluso si aceptamos que con ello se hacía referencia a un dominio que se extendía desde San Román hasta Carrión -y que ayudaría a confirmar la continuidad del dominio sobre Saldaña- tampoco podemos afirmar, sobre los documentos, que la integración de los tres territorios se produjera antes del 979. Como mucho, podemos situarla entre el 950, en el que el dominio sobre Saldaña parece reconocido, y el año 979.

Existen indicios que nos permitirían pensar que, a partir del último cuarto del siglo X, había un poder que ejercía una creciente influencia desde Carrión. Asî lo pondría de manifiesto la integración en su seno del territorio de Cueza. Este valle aparece en la documentación como una realidad geográfica aparentemente independiente. Se lo menciona por primera vez en un documento del año 950, en que aparece como lomba de Queza, que se localiza inter riuo Aratoi et Castrum Saldanie ${ }^{92}$. De ello se puede interpretar que no estaba englobada en el territorio saldañés -por más que se haga mención al conde en Saldaña-, ni tampoco, en principio, en ningún otro. La independencia del territorio se reafirma en un documento del año 977, que consigna la venta de la heredad que un tal Fortes tenía in Codisa, inter Aratoi et Sancti Laurenti ${ }^{93}$.

${ }^{87}$ I. Martín Viso, La feudalización, p. 43. Martín Viso plantea estas hipótesis para intentar explicar por qué el monasterio de Castañeda, que tenía propiedades en el entorno del valle desde el siglo $\mathrm{X}$, no expandió su dominio en el interior del mismo hasta el siglo XII.

${ }^{88}$ J. Gil Fernández et al., Crónicas Asturianas, Rotense, \$11 y Ad Sebastianum, §11. Saldaña aparece en la lista de las ciudades despobladas por Alfonso I y Fruela en las dos versiones de la crónica. Sabemos también que fue ceca visigoda (R. Pliego Vázquez, La moneda visigoda, p. 116).

${ }^{89}$ Algunas investigaciones al respecto en J.A. Abásolo Álvarez et al., Excavaciones en el yacimiento de la Morterona. Hay que tener en cuenta la riqueza arqueológica de esta zona para la época tardoantigua. Además de los estudios clásicos de P. de Palol, J. Cortes o J.A. Abásolo Alvarez sobre la villa de La Olmeda, merece destacar el esfuerzo de estudio territorial desarrollado, aunque también para época antigua y tardoantigua, en M. Nozal Calvo, El yacimiento de La Olmeda. Se trata de una estrategia de investigación que sería interesante adoptar para épocas posteriores.

90 J. Montenegro Valentín, Colección Diplomática, doc. 20.

${ }^{91}$ CDMS I, doc. 318.

92 CDMS I, doc. 129.

${ }^{93}$ CDMS I, doc. 291. 
En este texto, Cueza constituía una referencia suficiente: no era necesario señalar su pertenencia a una realidad territorial superior. Sin embargo, unos años más tarde, en una donación de García Gómez del año 984, se consignan unos bienes situados en la villa de Calzadilla, in territorio de Carrione in valle de Quoza: Cueza aparece, por tanto, integrada en el territorio de Carrión. Si confiamos en las datas de los documentos y en la precisión de las referencias geográficas, dicha integración habría ocurrido en algún momento entre el año 977 y el 984. Como señalé anteriormente, algunos autores entienden que, a la muerte de Ramiro III, los Banu Gómez trasladaron la capital de sus dominios a Carrión. Aunque los documentos puedan hablarnos, efectivamente, de una mayor presencia del grupo aristocrático en este centro, creo que resulta más interesante pensar no en términos de cambio de capitalidad, sino de afianzamiento de su dominio sobre la estructura territorial y de su capacidad para implantarse en el territorio de manera efectiva.

No obstante, dos donaciones de Osorio Díaz y de García Gómez que plantean problemas a la argumentación de un afianzamiento progresivo de los Banu Gómez sobre la cuenca del Carrión, ya que podrían mostrar la existencia de un conjunto de bienes patrimoniales anterior a lo que he indicado. El primero de ellos no supone, en realidad, mayor problema. En el texto, Osorio Díaz dona a Sahagún su castro que иосitant Muza. El hecho de que este magnate obtuviera el castro mediante una compraventa nos permite excluir tanto que este núcleo tuviera relevancia como centro sociopolítico y territorial ${ }^{94}$, como el que se tratara de bienes heredados. Por tanto, la existencia de dicha propiedad no nos obliga a retrotraer generacionalmente la presencia del grupo aristocrático en la zona ${ }^{95}$. Por el contrario, en otro documento se nos dice que García Gómez donó, en el año 984, su heredad en Calzadilla de la Cueza, que había obtenido, según dice, de avorum parentumque meorum. La posibilidad de que este conde gozara de propiedades heredadas, junto con la donación que Diego Muñoz hizo de una iglesia en Arconada, pone en cuestión la interpretación de la implantación de los Banu Gómez sobre la cuenca del Carrión que he realizado hasta el momento. Sin embargo, creo que siguen existiendo argumentos para mantener mi postura. Del mismo modo que la donación de la iglesia en Arconada no tenía por qué representar ni la implantación patrimonial ni jurisdiccional sobre el espacio, lo mismo podríamos decir de otra serie, bien de propiedades, bien de derechos, que los Banu Gómez podrían haber obtenido con anterioridad al control de la estructura territorial de Carrión. Es más, el hecho de que fueran propietarios no implica que disfrutaran desde un primer momento del dominio sobre el territorio, aunque sin duda éste habría sido un factor importante para el establecimiento de una autoridad efectiva sobre el mismo. La base patrimonial los habría situado en una posición ventajosa de cara al control de los mecanismos de poder propios de la estructura territorial. Prueba de ello sería esa "política de la tierra" que les vemos ejerciendo. De hecho, la cuantía de los bienes que le entregan a García Gómez a cambio de su heredad -un caballo valorado en 300 sueldos y un freno de plata de 100 sueldos- podría indicar que una cierta élite local estaba muy interesada en vincularse a una familia que representaba una escala superior de poder y que tenía una creciente influencia, hasta el punto de haber llegado a sustituir a los propios monarcas como destinatarios de la atención de los grupos locales dominantes ${ }^{96}$.

\footnotetext{
94 Véase L. de Castro, Cerámicas romanas de Viminacium. De ser cierta la identificación de Castro Muza con el núcleo romano de Viminacium, sería muy interesante conocer el desarrollo de este centro territorial y de su aparente vaciamiento de significado sociopolítico.

95 CDMS I, doc. 330.

${ }^{96}$ Iunez Mohomatel, propietario de Cueza, donó sus tierras a Ramiro II en algún momento antes del año 950 (CDMS I, doc. 129) (950.06.17).
} 
Más allá de la cuenca del Carrión, los Banu Gómez también lograron imponer en Liébana un dominio efectivo que se prolongaría durante décadas. La primera mención consigna a Gómez Díaz como conde en Liébana en el año $977^{97}$. Margarita Torres ha intentado buscar el motivo de esta expansión en el contexto político de debilidad que la monarquía habría atravesado al inicio del reinado de Ramiro III ${ }^{98}$. Aunque se trata de una cuestión pertinente, creo que es más interesante preguntarse por el tipo de estructuras territoriales que habrían estado funcionando en el momento en que los Banu Gómez se hicieron con el control esta región. Acaso su influencia en los desarrollos internos de dichas estructuras contribuyera tanto a la consolidación de éstas como a su participación en las mismas ${ }^{99}$. Por otro lado, no hay que olvidar que más adelante, en un momento en que contaban también con el respaldo musulmán, García Gómez logró hacerse con el dominio temporal de estructuras territoriales plenamente consolidadas como Ceón, Cea y Grajal ${ }^{100}$. Sin embargo, se trató de un dominio muy corto, profundamente ligado a la figura de García Gómez, quien contaba con el apoyo amirí, y que se disolvió poco después de la desaparición de este personaje.

En conjunto, estos casos de expansión territorial reflejan la solidez de la construcción central del dominio: la cuenca del Carrión. ¿Hubo también, además del impulso expansivo, una intensificación del dominio sobre los territorios centrales? Si tenemos en cuenta el patrimonio con el que contaban ya en el siglo XI, podríamos pensar que sí, y que además esto fue la garantía de su participación en un nuevo sistema de poder basado en unas relaciones feudales progresivamente consolidadas. De ahí que un estudio en la línea que propone J.M. Mínguez resulte esencial para comprender el paso de un modelo de ejercicio de poder basado en el dominio sobre territorialidades preexistentes, a otro, a partir fundamentalmente del segundo tercio del siglo XI, en el que la propiedad y participación en la estructura institucional de la monarquía irían adquiriendo mayor importancia.

Con ello no quiero decir que la relación con la monarquía no fuera importante ya en el siglo X. El caso de los Ansúrez muestra precisamente lo contrario. Ahora bien, a la vista de la cohesión interna del dominio de los Banu Gómez y la aparentemente nula intervención directa de la monarquía en estas zonas, ¿cuáles fueron las relaciones entre el grupo aristocrático y los reyes asturleoneses en el siglo X? Una primera pista la encontramos en la batalla de Tebular. M. Torres ha visto en el Abolmondar Albo que acompaña a Nuño Fernández y a Fernando Ansúrez una forma alterada de Abd-al-Mundir o, en definitiva, una arabización de Munio. La autora señala que posiblemente se tratara de Munio Gómez, cuyo hijo en la crónica, Diego, no sería sino el propio Diego Muñoz. Creo que no hay mayor problema en asumir esta hipótesis, no sólo por la coincidencia en los nombres, sino también porque la pléyade de personajes que participan en Tebular refleja a los que serán los tres grupos aristocráticos principales al este del Cea desde mediados del siglo X: los Banu Gómez, los Ansúrez y los condes castellanos. Tebular, así como el episodio de rebeldía de Alfonso IV, no son por otra parte, sino uno más de una serie de episodios violentos que se sucederían a lo largo del siglo X y que enfrentarían a los Banu Gómez con la monarquía asturleonesa. En el año 944, Diego Muñoz y Fernán González se rebelaron contra Ramiro II, aunque fueron derrotados. Tenemos también noticias de las

${ }^{97}$ CDMS I, doc. 288.

${ }^{98}$ M. Torres, Linajes nobiliarios, pp. 249-251. La autora recurre en su argumento a la idea de la creación de una "frontera interior" frente a las ambiciones expansionistas castellanas (ibidem, p. 251).

99 J. Marcos Martínez; L. Mantecón Callejo, El castillo del monte Subiedes.

${ }^{100}$ CDMS II, doc. 392; CDMS I, doc. 263; CDMS II, doc. 384. 
usurpaciones de villas por Gómez Díaz ${ }^{101}$. El punto álgido tiene lugar en el año 990, cuando García Gómez logró usurpar, gracias al respaldo musulmán, el gobierno de la ciudad de León ${ }^{102}$. A pesar de esta actitud de enfrentamiento hacia a la monarquía, las evidencias documentales muestran que, desde la época de Osorio y Diego Muñoz, los Banu Gómez estuvieron ligados de una forma u otra a los monarcas leoneses y participaron de sus instituciones ${ }^{103}$. Lo interesante, por tanto, es considerar la base de poder que les permitía mantener esta posición a caballo entre la integración en el reino y el mantenimiento de una política propia capaz de desafiar a la monarquía. Como hemos visto, lograron hacerse con un dominio de grandes dimensiones e intensidad, lo que los situaba como mediadores clave para la integración de esos espacios en el reino asturleonés. A la vez, este marco territorial habría ofrecido una serie de recursos suficientes como para otorgarles una gran capacidad de actuación. Su presencia en los círculos aristocráticos en posiciones tan importantes como las que llegarían a ocupar Osorio y Diego Muñoz habría podido deberse a la necesidad de los reyes de neutralizarlos mediante su incorporación plena, aunque en último término fallida, al marco institucional de la monarquía. Quizá lo ocurrido en Tebular facilitó inicialmente la labor a los monarcas, aunque una derrota militar no se habría podido traducir en la desarticulación de una red patrimonial y de poder tan sólidamente construida como la que los Banu Gómez estaban desarrollando.

\section{CONCLUSIÓN: LOS MECANISMOS DE INTEGRACIÓN TERRITORIAL ENTRE EL CEA Y EL PISUERGA EN EL SIGLO X}

A lo largo de los epígrafes anteriores hemos podido comprobar que existen diferencias importantes en cuanto al desarrollo de las estructuras territoriales y de los grupos aristocráticos de esta región. Si bien en ambos casos las fuentes nos muestran a estos magnates al frente de estructuras territoriales de cierta complejidad, construidas mediante la absorción o integración de territorialidades previamente constituidas, tanto sus condiciones de partida como sus trayectorias históricas particulares divergen profundamente. Desde el punto de vista estructural, es posible que los territorios contemplados no fueran tan distintos. Sin embargo, el diferente grado de imbricación entre las estructuras territoriales particulares y las élites regionales, así como la relación entre éstas y la monarquía asturleonesa, determinó la construcción de escalas de acción analíticamente similares en cuanto a su complejidad, pero con una concreción histórica muy diferente en cada caso.

Como hemos visto, la situación de partida habría estado definida por la capacidad de cada grupo para llevar a cabo tanto la consolidación patrimonial como la creación de una red de poder que le permitiera ejercer de manera efectiva su dominio sobre las estructuras territoriales que controlaba. Los Ansúrez parecen haber logrado alcanzar un cierto grado de preeminencia en el seno del condado castellano, aunque luego fueron desplazados. En Monzón sabemos que dispusieron de la capacidad y de los mecanismos para generar una nueva red de poder, si bien no antes de la segunda mitad del siglo X y sin que ello parezca haberse traducido en una integración plena en

${ }^{101}$ CDCL II, doc. 508 (985.11.16); CDMS II, doc. 444 (1036.01.20).

102 CDCL III, docs. 534 y 535. Los enfrentamientos entre los Banu Gómez y la monarquía se prolongaron incluso aún más en el tiempo, aunque ya en el siglo XI (CDCL III, doc. 829).

103 Osorio Muñoz aparece en el año 936 como confirmante en un documento dado por Ramiro II (CDMD, doc. 8). A partir de entonces, los Banu Gómez aparecen recurrentemente en los diplomas regios, siempre entre los primeros en la lista de confirmantes. 
la estructura territorial. Da la sensación de que su poder allí se basó no en su infiltración en estructuras territoriales previamente constituidas, sino en la imposición de su autoridad sobre las mismas.

Los Banu Gómez, por su parte, se vieron inmersos en un largo proceso de producción de una estructura territorial y un ámbito de poder propios, si bien debido a la heterogeneidad de las situaciones locales o supralocales particulares -como demuestra el caso de Saldaña - no lograron, como pretendía la historiografía tradicional, construir un dominio uniforme sobre el espacio comprendido en el entorno del Carrión. No obstante, a diferencia de los Ansúrez, parecen haber jugado un papel más importante en el proceso de consolidación de las estructuras territoriales que dominaron, lo que les habría permitido hacer un uso más efectivo de las posibilidades de acción que éstas pudieran ofrecerles, así como, en último término, generar, gracias a la integración de cuatro -si sumamos Liébana-territorios bajo un mismo dominio, una escala de acción superior. Por otra parte, en su caso, la consolidación patrimonial y el afianzamiento político fueron de la mano, lo que garantizó su posición no sólo a lo largo del siglo X, sino también del siglo XI.

Este contraste entre una y otra situación podría indicar que tanto la capacidad de acción de los Ansúrez como su posición en Monzón dependían, fundamentalmente, del respaldo de los reyes asturleoneses y del apoyo que les proporcionaba el marco institucional del reino. Si bien el dominio patrimonial y político de los Banu Gómez muestra una gran coherencia espacial y, por eso mismo, una gran solidez, los Ansúrez estaban mucho más expuestos a los vaivenes que pudieran sufrir sus relaciones con la monarquía. Acaso por ello la familia desapareció de las fuentes tras el turbulento acceso de Vermudo II al trono. En todo caso, esto no significa que los Banu Gómez no se beneficiaran de su relación con escalas superiores de poder. Desde el punto de vista de la monarquía, su integración en las altas esferas de las instituciones asturleonesas sería el reflejo de un intento de asimilación por parte de los monarcas. Fue un intento fallido en la medida en que supusieron un problema constante a lo largo del siglo X: la integración, por tanto, parece haber sido más nominal que efectiva, al menos en este siglo. Los reyes asturleoneses habrían carecido de la fuerza necesaria como para proyectar su poder sobre este espacio y controlar los mecanismos internos para el ejercicio de la autoridad. En Monzón, por el contrario, los monarcas pudieron actuar de manera muy diferente. Se trataba de un espacio en el que la monarquía intervino en una fecha muy temprana y en el que, a través de otros actores -el presbítero Gratón, el monasterio de San Isidro de Dueñas- había ejercido ya una cierta influencia. Desde este punto de vista, es muy difícil considerar que el proceso de producción del espacio del condado de Monzón fuera el resultado de la acción de una lógica aristocrática, como señalaba J. Escalona. Los Ansúrez parecen haber estado supeditados a la lógica institucional asturleonesa.

Estas diferencias subregionales nos muestran la existencia de al menos dos procesos alternativos para la integración territorial en el marco del reino asturleonés. Después de insistir en la importancia de una consideración detenida de cada realidad histórica particular, resulta difícil proponer una modelización a partir de cada uno de estos casos. Sin embargo, existen características relevantes que sí cabría resaltar de cara a una consideración global del proceso de implantación de la monarquía en el norte de la Meseta en el siglo X En este sentido, el empleo de un marco conceptual basado en términos como estructura territorial, escala o complejidad, nos permite rastrear la forma en que determinados elementos pudieron haber operado en cada uno de los distintos niveles constitutivos del reino. Y es que, en realidad, los condicionantes y posibilidades que ofrecían los distintos marcos socioespaciales a los distintos actores, en cualquiera de las escalas, no eran tan diferentes. Monzón pone de manifiesto la capacidad de la monarquía para llevar a cabo, en un determinado momento, la proyección de su poder sobre un cierto espacio. La influencia monárquica anterior garantizó 
durante un tiempo la estabilidad de la estructura territorial que así se generó, si bien ésta no alcanzó el grado de cohesión que sí tenían los territorios bajo dominio de los Banu Gómez. Si no existían los cauces necesarios para que el poder permeara a través de las escalas inferiores, la imposición de una figura externa sobre una estructura territorial más o menos consolidada no garantizaba el ejercicio continuado del dominio sobre el territorio. El efímero control que García Gómez tuvo sobre Ceón, Cea y Grajal ilustra también este problema. La integración territorial pasaba, por tanto, por la apropiación de aquellos mecanismos que hacían efectiva la implantación territorial. Por ello para los reyes la incorporación de élites como los Banu Gómez a las instituciones del reino resultaba fundamental para la creación de canales a través de los cuales ejercer un dominio efectivo.

El documento que consigna la donación de Asur Fernández del año 943 plantea otra posibilidad, ya que parece mostrar que el dominio también se podía basar, al menos temporalmente, en el control de una estructura territorial si ésta tenía un grado suficiente de formalización. Esto contrasta con estructuras como los terminos de Teodisclo o el de Munio Gómez, que muestran una gran fluidez. Se trataba de estructuras territoriales en la medida en que constituían los marcos socioespaciales de ejercicio de la acción de estos personajes. No obstante, la reproducción de estos marcos estaba condicionada por la reproducción de la situación social de quienes ejercían dicho dominio, a diferencia, como vimos, de estructuras territoriales consolidadas como Cea o Grajal, que cambiaron de manos. Así pues, las distintas escalas de acción a través de las cuales la monarquía buscaba implantar su poder sobre el espacio estaban constituidas por estructuras territoriales con un grado variable de formalización, que era menor, al menos en la primera mitad del siglo X, en las escalas locales. En el otro extremo, la escala de acción de los reyes asturleoneses constituía precisamente un techo de poder altamente formalizado: el que representaba la monarquía, entendido como una estructura territorial compleja que integraba varios niveles organizativos de distinta naturaleza. A pesar de los múltiples enfrentamientos entre los monarcas y los distintos grupos aristocráticos, ninguno de estos habría podido situarse estructuralmente por encima de la escala de poder definida por el reino, como demostraría, por ejemplo, la usurpación de García Gómez en el año 990. No obstante, a lo largo del siglo X, se observa una tendencia que culmina en el siglo XI con la creación de un sistema de tenencias y la formalización y homogeneización relativa de las relaciones espaciales de subordinación en el seno de los antiguos territorios, lo que supondría, a su vez, un nuevo desarrollo cualitativo en la construcción interna del reino. Aunque habría que analizarlo con detalle, podemos ver en ello un intento de la monarquía por garantizar la reproducción de su dominio independientemente de las condiciones espaciales particulares que funcionaban en las escalas inferiores. En cualquier caso, habrá que esperar, pues, al segundo tercio del siglo XI para ver un cambio notable en cuanto a la estructuración territorial del reino y las fórmulas de dominio territorial.

Finalmente, lo que hemos visto confirma que términos tales como conde o condado sólo pueden ser considerados, analíticamente, como la representación -en las fuentes y en la historiografía- de marcos socioespaciales y de las capacidades de acción de determinados personajes. Formalmente, el nivel de complejidad estructural alcanzado en los dominios de los Banu Gómez y en el de los Ansúrez puede ser considerado como equivalente, lo que explicaría que varios de los miembros de estos grupos aristocráticos aparezcan en las fuentes como condes y que, en el caso de Monzón, la estructura territorial sea calificada de condado. La diferencia estriba, como hemos visto, en el contenido histórico que se oculta tras tales representaciones. Precisamente, la perspectiva adoptada aquí ha permitido mostrar que estos territorios tuvieron una historia que no fue, ni mucho menos, ni la que el reino asturleonés primero, ni la que la historiografía después, impusieron sobre ellos. 


\section{BIBLIOGRAFÍA CITADA}

Abásolo Álvarez, José Antonio; Cortes Álvarez de Miranda, Javier; Pérez RodríguezAragón, Fernando; Vighi, Almudena, Excavaciones en el yacimiento de la Morterona, Saldaña (Palencia), Palencia, Institución Tello Téllez de Meneses, 1984.

Álamo, Juan de, Colección diplomática de San Salvador de Oña: (822-1284), Madrid, Consejo superior de Investigaciones Científicas - Escuela de Estudios Medievales, 1950.

Barbero, Abilio; Vigil, Marcelo, La formación del feudalismo en la Península Ibérica, Barcelona, Crítica, 1978.

Bernhardt, John W., Itinerant Kingship \& Royal Monasteries in Early Medieval Germany c. 936-1075, Cambridge, University Press, 1993.

Blair, John, The Church in Anglo-Saxon Society, Oxford, University Press, 2005.

Botella Pombo, Esperanza, La serna: ocupación, organización y explotación del espacio en la Edad Media (800-1250), Santander, Tantin, 1988.

Castellanos, Santiago; Martín Viso, Iñaki, The local articulation of central power in the north of the Iberian Peninsula, "Early Medieval Europe" 13 (2005), pp. 1-42.

Castro, Lázaro de, Cerámicas romanas de Viminacium. Calzadilla de la Cueza (Palencia), "Sautuola" 1 (1975), pp. 251-265.

Cavero Domínguez, Gregoria; Martín López, Encarnación, Colección documental de la catedral de Astorga, I (646-1126), León, Centro de Estudios e Investigación "San Isidoro", 1999.

Escalona, Julio, Aproximación a un análisis comparativo de la territorialidad en los siglos IX-XI: el Territorium legionensis y el Condado de Castilla, en Cuesta Duarte, José Ignacio de la (ed.), Monasterios, espacio y sociedad en la España cristiana medieval, Logroño, Instituto de Estudios Riojanos, 2010, pp. 271-291.

Estepa, Carlos, Problemas de terminología en la vida urbana de León en la Edad Media, "Archivos leoneses" 52 (1972), pp. 99-124.

Estepa, Carlos, El alfoz castellano en los siglos IX al XII, "En la España Medieval” 4 (1984), pp. 305-341.

Estepa, Carlos, La Castilla primitiva (750-931): condes, territorios y villas, en Fernández Conde, F.J.; García de Castro Valdés, C. (coords.), Poder y simbología en Europa, siglos VIII-X, Oviedo, Trea, 2009, pp. 261-278.

García de Cortázar, José Ángel, El dominio del monasterio de San Millán de la Cogolla (siglos X a XIII). Introducción a la historia rural de Castilla altomedieval, Salamanca, Universidad de Salamanca, 1969.

García de Cortázar, José Ángel, La serna, una etapa del proceso de ocupación y explotación del espacio, "En la España Medieval" 1 (1980), pp. 115-128.

García Guinea, Miguel Ángel; González Echegaray, Joaquín; Madariaga de la Campa, Benito, El Castellar, Villajimena (Palencia): Memoria de Excavaciones, "Publicaciones de la Institución Tello Téllez de Meneses" 23 (1963), pp. 123-158.

García Guinea, Miguel Ángel; Iglesias Gil, José Manuel; Caloca, Pablo, Excavaciones de Monte Cildá, Olleros de Pisuerga (Palencia): Campaña de 1966 a 1969, "Publicaciones de la Institución Tello Téllez de Meneses" 34 (1974), pp. $1-95$.

García Guinea, Miguel Ángel; San Miguel Ruiz, José Antonio; González Echegaray, Joaquín, Excavaciones en Monte Cildá, Olleros de Pisuerga (Palencia): Campañas de 1963-1965, "Publicaciones de la Institución Tello Téllez de Meneses" 26 (1968), pp. 1-68.

ANUARIO DE Estudios MEdievales, 42/2, julio-diciembre 2012, pp. 601-628

ISSN 0066-5061, doi:10.3989/aem.2012.42.2.08 
Gil Fernández, Juan; Moralejo, José Luis; Ruiz de la Peña, Juan Ignacio, Crónicas Asturianas, Oviedo, Universidad, Departamento de Historia Medieval, Departamento de Filología Clásica, 1985.

Godelier, Maurice, Lo ideal y lo material, Madrid, Taurus, 1989.

González, Julio, Siglos de Reconquista, en González, Julio (coord.), Historia de Palencia, vol. 1. Edades Antigua y Media, Palencia, Diputación Provincial, 1984, pp. 155-216.

Guerrero Lafuente, María Dolores; Álvarez Castillo, María Angustias, Los inicios del monacato en Palencia: Santa Eufemia de Cozuelos, en Actas del III Congreso de Historia de Palencia: fuentes documentales, sociedad y economía e historia de las instituciones. T. II, Historia medieval, Palencia, Diputación de Palencia, 1995, vol. II, pp. 173-194.

Hayyān, Ibn, Crónica del califa 'Abdarrahmān III and-Nāsirir entre los años 912 y 942 (al-Muqtabis V), María Jesús Viguera, y Federico Corriente (trads.), Zaragoza, Anubar, 1981.

Herrero de la Fuente, Marta, Colección Diplomática del Monasterio de Sahagún (857-1230), II (1000-1073), León, Centro de Estudios e Investigacion "San Isidoro", 1988.

Innes, Matthew, State and Society in the Early Middle Ages. The Middle Rhine Valley 400-1000, Cambridge, Cambridge University Press, 2000.

Larrea Conde, Juan José, Aldeas navarras y aldeas del Duero: notas para una perspectiva comparada, "Edad Media. Revista de Historia" 6 (2004), pp. 159-181.

Lucas Álvarez, Manuel, La documentación del Tumbo A de la catedral de Santiago de Compostela. Estudio y edición, León, Centro de Estudios e Investigación "San Isidoro", 1997.

Marcos Díez, David, La abadía de Santa María de Husillos. Estudio y colección documental, Valladolid, Universidad de Valladolid, 2009. (Tesis Doctoral).

Marcos Martínez, Javier; Mantecón Callejo, Lino, El castillo del monte Subiedes (Camaleño, Liébana, Cantabria). Control del territorio lebaniego en la Alta Edad Media, "Territorio, Sociedad y Poder" 4 (2009), pp. 95-130.

Martín Iglesias, José Carlos, Los Annales Castellani Antiquiores y Annales Castellani Recentiores: edición y traducción anotada, "Territorio, Sociedad y Poder" 4 (2009), pp. 203-226.

Martín Viso, Iñaki, La feudalización del valle de Sanabria (siglos X-XIII), "Studia Historica. Historia Medieval" 9 (1993), pp. 35-55.

Martín Viso, Iñaki, Repoblaciones, territorios, iglesias y santos: los valles del Duratón y del Riaza (siglos X-XIII), en El Medievo en el Duero Oriental. Historia y Arte románico, Aranda de Duero, Ayuntamiento 2008, pp. 265-292.

Martín Viso, Iñaki, La monarquía asturleonesa en el Bierzo (siglos IX y X), (en prensa).

Martínez Díez, Gonzalo, El obispado de Palencia en el siglo X, en Liber amicorum Prof. Don Ignacio García de la Concha, Oviedo, Universidad, 1986, pp. 339-348.

Martínez Díez, Gonzalo, Los condados de Carrión y Monzón: sus fronteras, en Actas del I Congreso de Historia de Palencia, Fuentes documentales y Edad Media, Palencia, Diputación Provincial, 1987, vol. II, pp. 245-274.

Martínez Díez, Gonzalo, La familia condal de Carrión, en Actas del III Congreso de Historia de Palencia: fuentes documentales, sociedad y economía e historia de las instituciones. Historia medieval, Palencia, Diputación de Palencia, 1995, vol. II, pp. 551-604.

Martínez Díez, Gonzalo, Colección documental del monasterio de San Pedro de Cardeña, Burgos, Caja de Ahorros y Monte de Piedad del Círculo Católico de Obreros de Burgos, 1998. 
Martínez Díez, Gonzalo, El condado de Castilla (711-1038). La historia frente a la leyenda, Valladolid, Junta de Castilla y León, 2005.

Mínguez, José María, Colección diplomática del Monasterio de Sahagún (siglos IX y X), León, Centro de Estudios e Investigacion "San Isidoro", 1976.

Mínguez, José María, Las sociedades feudales, vol. 1: Antecedentes, formación y expansión: (siglos VI al XIII), Madrid, Nerea,1994.

Mínguez, José María, La frontera del Carrión entre los siglos X-XII: bisagra y conflicto, ponencia presentada en el Congreso Internacional Regnum Legionis (910-1230), celebrado en León entre el 25 y el 29 de octubre de 2010, [S.1., s.n.], 2010.

Montenegro Valentín, Julia, En torno a los orígenes familiares de Diego Muñoz, el primer conde de Saldaña, en Actas del I Congreso de Historia de Palencia. Fuentes documentales y Edad Media, Palencia, Diputación Provincial, 1987, vol. II, pp. 339-352.

Montenegro Valentín, Julia, Colección Diplomática de Santa María de Piasca (857. 1252), Santander, Consejería de Cultura, Educación, Juventud y Deporte, 1991.

Montenegro Valentín, Julia, Santa María de Piasca. Estudio de un territorio a través de un centro monástico (857-1252), Valladolid, Universidad de Valladolid, 1993.

Nozal Calvo, Miguel, El yacimiento de La Olmeda. La villa y el territorio, en Actas del III Congreso de Historia de Palencia. Prehistoria, arqueología e historia antigua, Palencia, Diputación Provincial, 1995, vol. I, pp. 315-340.

Paasi, Ansii, Place and region: looking through the prism of scale, "Progress in $\mathrm{Hu}-$ man Geography" 28/4 (2004), pp. 536-546.

Pérez Celada, Julio Antonio, Sobre el origen de Carrión de los Condes y sus funciones en la articulación territorial: del poblamiento vacceo a la configuración medieval, en Rodríguez Colmenero, Antonio (coord.), Los orígenes de la ciudad en el noroeste hispánico. Actas del Congreso Internacional, Lugo, Diputación Provincial, 1998, pp. 1411-1424.

Pérez Celada, Julio Antonio, Documentación del Monasterio de San Zoilo de Carrión (1047-1300), Palencia, Garrido Garrido, 1986.

Pérez Celada, Julio Antonio, El monasterio de San Zoilo de Carrión. Formación, estructura y decurso de un señorío castellano-leonés (siglos XI al XVI), Burgos, Universidad de Burgos, 1997.

Pérez de Urbel, Justo, Historia del Condado de Castilla, Madrid, Consejo Superior de Investigaciones Científicas, Escuela de Estudios Medievales, 1945.

Pérez de Urbel, Justo, Sampiro: su crónica y la monarquía leonesa en el siglo $X$, Madrid, [s.n.], 1952.

Pliego Vázquez, Ruth, La moneda visigoda, vol. I, Sevilla, Universidad de Sevilla, 2009.

Quirós Castillo, Juan Antonio, Early Medieval Villages in Spain in the light of European experience. New approaches in peasant archaeology, en Quirós Castillo, Juan Antonio (eds.), The Archaeology of Early Medieval Villages in Europe, Bilbao, Universidad del País Vasco, 2009, pp. 13-26.

Reglero de la Fuente, Carlos Manuel, El monasterio de San Isidro de Dueñas en la Edad Media. Un priorato cluniacense hispano (911-1478). Estudio y colección documental, León, Centro de Estudios e Investigación "San Isidro", 2005.

Rodríguez Fernández, Justiniano, Ramiro II, rey de León, Madrid, Consejo Superior de Investigaciones Científicas, Instituto Jerónimo Zurita, Escuela de Estudios Medievales, 1972. 
Rodríguez González, Ángel, El tumbo del monasterio de San Martín de Castañeda, León, Centro de Estudios e Investigación "San Isidro", 1973.

Rowlands, Michael, Centre and periphery. A review of the concept, en Kristiansen, Kristian; Rowlands, Michael, Social Transformations in Archaeology. Global and Local Perspectives, London, Routledge, 1998, pp. 219-242.

Ruiz Asencio, José Manuel, Colección documental del archivo de la Catedral de León (775-1230), III (986-1031), León, Centro de Estudios e Investigación “San Isidro",1987.

Ruiz Asencio, José Manuel; Ruiz Albi, Irene; Herrero Jiménez, Mauricio, Colección documental del monasterio de San Román de Entrepeñas (940-1608), León, Centro de Estudios e Investigación "San Isidro", 2000.

Sack, Robert David, Human Territoriality. Its Theory and History, Cambridge, Cambridge University Press, 1986.

Sáez, Emilio, Los ascendientes de San Rosendo: notas para el estudio de la monarquía astur-leonesa durante los siglos IX-X, Madrid, Consejo Superior de Investigaciones Científicas, Instituto Jerónimo Zurita, 1948.

Sáez, Emilio, Colección documental del archivo de la Catedral de León (775-1230), I (775-952), León, Centro de Estudios e Investigación "San Isidro", 1987.

San Martín Payo, Jesús, Las primeras donaciones de los condes de Monzón a Santa María de Husillos, "Publicaciones de la Institución Tello Téllez de Meneses" 59 (1988), pp. 297-350.

Sánchez Badiola, Juan José, La configuración de un sistema de poblamiento y organización del espacio: el territorio de León (siglos IX-XI), León, Universidad de León, 2002.

Sánchez Belda, Luis, Cartulario de Santo Toribio de Liébana, Madrid, Patronato Nacional de Archivos Históricos, 1948.

Smith, Neil; Dennis, Ward, The Restructuring of Geographical Scale: Coalescence and Fragmentation of the Northern Core Region, "Economic Geography" 63/2 (1987), pp. 160-182.

Torres, Margarita, Linajes nobiliarios de León y Castilla (siglos IX-XIII), Valladolid, Junta de Castilla y León, 1999.

Vaca Lorenzo, Ángel, El Obispado de Palencia desde sus orígenes hasta su definitiva restauración en el siglo XI, "Hispania Sacra" 52/105 (2000), pp. 21-72.

Vigil-Escalera Guirado, Alfonso; Quirós Castillo, Juan Antonio, Early Medieval Rural Societies in North-Western Spain: Archaeological Reflections of Fragmentation and Convergence, en Escalona, Julio; Reynolds, Andrew (eds.), Scale and Scale Change in the Early Middle Ages. Exploring Landscape, Local Society and the World Beyond, Turnhout, Brepols, 2011, pp. 33-60.

Wickham, Chris, Framing the Early Middle Ages. Europe and the Mediterranean, 400-800, Oxford, Oxford University Press, 2005.

Fecha de recepción del artículo: febrero 2011

Fecha de aceptación y versión final: julio 2011 